\title{
Synthesis of 7,8-dihydroxyflavone functionalized gold nanoparticles and its mechanism of action against Leishmania donovani
}

\section{Pragya Prasanna}

NIPER Hajipur: National Institute of Pharmaceutical Education and Research Hajipur

\section{Prakash Kumar}

NIPER Hajipur: National Institute of Pharmaceutical Education and Research Hajipur

\section{Saptarshi Mandal}

Indian Institute of Technology Patna

\section{Saurabh Kumar}

NIPER Hajipur: National Institute of Pharmaceutical Education and Research Hajipur

\section{Tanvi Payal}

NIPER Hajipur: National Institute of Pharmaceutical Education and Research Hajipur

\section{Ugir Hossain Sk.}

Chittaranjan National Cancer Research Center: Chittaranjan National Cancer Institute

\section{Prolay Das}

Indian Institute of Technology Patna

\section{Ravichandiran}

NIPER Hajipur: National Institute of Pharmaceutical Education and Research Hajipur

Debabrata Mandal ( $\sim$ debabrataman@gmail.com )

National Institute of Pharmaceutical Education and Research Hajipur https://orcid.org/0000-00016413-8509

\section{Research}

Keywords: Functionalized gold nanoparticle, DHF, DHF-GNP, arginase inhibition, drug-resistant Parasite, iNOS activation

Posted Date: March 17th, 2021

DOI: https://doi.org/10.21203/rs.3.rs-37873/v3

License: (c) (i) This work is licensed under a Creative Commons Attribution 4.0 International License. Read Full License 


\section{Abstract}

Background - The synthesis of gold nanoparticles (GNPs) using drugs, synthetic and natural compounds, proteins, nucleic acids have become beneficial due to improved biological activity coupled with reduced cytotoxicity. In this regard, green synthesis of GNPs using plant extract enriched with flavonoids has shown increased attention due to improved antimicrobial efficacy, greater solubility, and better bioavailability of the flavonoid conjugated with GNPs. We have used 7, 8 dihydroxyflavone (DHF), a flavonoid that is enriched in plants and known for neurotropic and antioxidant activities, for the synthesis of GNP. In this report, we have investigated the synthesis, characterization, and biological activity of DHF synthesized GNP against the parasite Leishmania donovani.

Results - Synthesized DHF functionalized GNPs (DHF-GNPs) are $~ 35 \mathrm{~nm}$ in size with zeta potential values of $-34.1 \mathrm{mV}$, as observed from DLS studies. UV-Visible spectroscopy and FT-IR analysis confirm successful conjugation of DHF over GNP. TEM imaging shows the uniform size and spherical distribution of NPs. Against $L$. donovani promastigotes $\mathrm{IC}_{50}$ for DHF and DHF-GNP is $\sim 120 \mu \mathrm{M}$ and $\sim 40 \mu \mathrm{M}$ respectively. In ex vivo, amastigote model $\mathrm{IC}_{50}$ for DHF and DHF-GNP is $\sim 40 \mu \mathrm{M}$ and $\sim 22 \mu \mathrm{M}$ respectively. A dose-dependent increase of gold content as measured by atomic absorption spectroscopy (AAS) confirms the internalization of GNPs by macrophages. Even with $1000 \mu \mathrm{M}$ of DHF-GNP, cytotoxicity is only $\sim 30 \%$ compared to $\sim 50 \%$ cytotoxicity of $40 \mu \mathrm{M}$ c-GNP, on THP1 cells. It indicates high biocompatibility of DHF-GNP over c-GNP. In DHF-GNP treated parasites, the activity of arginase decreases in a dose-dependent manner as evident from gene expression and enzyme-based studies.

Supplementation of treated cells with ornithine, metabolite of arginase, shows the highest recovery from death. This indicates inhibition of arginase as the main reason for parasite death. Induction of IFN- $y$ and reduction IL-12 cytokine response shows a possible $T_{h} 1 / T_{h} 2$-mediated cell death. Also, DHF and DHFGNP are equally effective against sensitive and drug-resistant strains of $L$. donovani.

Conclusion - Low cytotoxicity and high biological activity may provide an alternative but improved delivery of DHF whose solubility increases due to conjugation with GNP. Further efficacy against drugresistant strains could be beneficial instead of conventional chemotherapy for leishmaniasis.

\section{Background}

Gold nanoparticles (GNPs) are the most widely studied metal NPs because of their contribution to various applications [1]. Due to ease of surface modification and biocompatibility, GNPs emerge as an attractive candidate for delivering small molecules [2], antimicrobial agents [3], peptides [4], proteins [5] and nucleic acids [6] to their targets. GNP-based drug delivery is popular due to the ease of GNPs functionalization with antimicrobial agents, biological or chemical methods of synthesis, controlled drug delivery, and multiple-targets of biological action with their ability to penetrate biological membranes. Despite several favourable properties such as the ability to self-assemble, encapsulate drugs and stability in biological systems [7], the capability to kill drug-resistant microbes [8], widespread usage of NPs is restricted by its toxicity on living organisms as well as the environment [9]. Conventional chemical methods of synthesis 
render GNPs toxic during delivery in biological systems. Green synthesis provides a solution to this problem [10]. It is regarded as safe, cost-effective, energy-efficient, and environmentally compatible [11]. This technique exploits the reducing power of biological systems like plants, algae, fungi and bacteria and natural products, e.g., polysaccharides, phytochemicals, flavonoids, etc. [12]. Many several biological sources have been identified as reductants to generate NPs of desirable size, shape and properties [13]. Different plant extracts have been used for the green synthesis of GNP with improved biocompatibility and enhanced biological activity $[14,15]$. With further advancement in the understanding of green synthesis, raw plant extracts used in green synthesis were gradually replaced with extracted chemicals like alkaloids, flavonoids, tannins, terpenoids, phenolic acids, carotenoids, etc [10, 16]. High-performance liquid chromatography (HPLC) analysis of NPs synthesized using Withania somnifera leaf extract showed the role of flavonoids in green synthesis [17]. several studies confirmed that flavonoids might be considered major contributors and the best plant-derived materials for green synthesis [18] of NPs. The presence of hydroxy $(-\mathrm{OH})$ and carbonyl $(-\mathrm{CO})$ groups along with aromatic rings provides a high reducing potential of flavonoids. A large number of flavonoids are sparingly water-soluble with compromising bioavailability [19] even though they have significant antimicrobial properties. Synthesis of nanoparticles with flavonoids has shown increased bioavailability and aqueous solubility for the flavonoids [14]. Members of flavonoids exhibit anticancer, antimicrobial, antioxidant, anti-inflammatory and neuroprotective properties [20,21]. Flavonoid functionalized GNPs showed significantly improved biological properties in comparison with free flavonoids [18]. Enhancement of biological activity of GNPs in comparison to both flavonoids and NPs alone has been reported [22] [14]. Incorporation of resveratrol, quercetin, baicalein, epigallocatechin gallate (EGCG) on metal ions showed an improved antioxidant effect, anti-inflammatory effect, oral bioavailability and reduced toxicity [22, 23]. Apart from natural flavonoids, semi-synthetic or synthetic flavonoids have also shown great potential in inhibiting microbes. The synthesis usually includes substitution in hydroxy groups, the addition of halogens or other heteroatomic rings [24].

Leishmaniasis is the second-largest protozoal disease after malaria and one of the most neglected diseases. It is still a major health concern in developing countries like India. It affects around 12 million people in 98 countries and is still a major health concern in developing countries like India. It is transmitted by sandflies (Phlebotomus spp.), a small biting mosquito, which breeds in moist soil, forest areas, or caves and feed from infected animal reservoir hosts or humans [25]. An asymptomatic condition like postkala-Azar dermal leishmaniasis (PKDL) poses a threat of recurrent disease outbreak. Among all types, the visceral leishmaniasis (VL) caused by Leishmania donovani (LD) is fatal and most challenging one to control. Although there are significant developments of NPs as antileishmanial agents, their application is severely restricted due to toxicity issues. In recent years, several natural and synthetic flavonoids are considered as lead compounds for developing antiprotozoal agents. Compounds like quercetin, 7, 8- dihydroxyflavone, Luteolin, Apigenin, Fisetin, and Kaempferol had been shown to inhibit LD at very low concentrations in vitro [26, 27]. Quercetin and some of its glycoside derivatives have been shown to be active after oral administration on the $L$. amazonensis in vivo mice model $[28,29]$. 7, 8dihydroxyflavone (DHF) is a naturally occurring flavonoid obtained from plants. It was discovered while 
searching for molecules that imitate the function of brain-derived neurotrophic factors [30]. DHF rescues cells from damage and death caused by oxidative stress [31]. DHF also reduced the levels of inflammation-causing nitric oxide, prostaglandin E2 (PGE2), TNF-alpha, and IL-6 in macrophages [32]. DHF treatment failed to protect LD and Trypanosoma brucei infected mice in vivo although very high activity was found in vitro [28]. Poor bioavailability of DHF is likely the cause of failure in mice models. In this study, we synthesized GNP using DHF as a reducing and capping agent. We evaluated the antileishmanial potential of DHF-GNP and its mechanism of action in reference to DHF.

\section{Materials And Methods}

Medium 199, Fetal Bovine Serum (FBS), RPMI-1640, Penicillin/Streptomycin antibiotic solution, Bradford reagent, DNase I were purchased from ThermoFisher Scientific. Tetrachloroauric (III) acid trihydrate $\left(\mathrm{HAuCl}_{4}\right.$ ), Trypan blue, Triton X-100, L. arginine, a -isonitrosopropiophenone (ISPF), Nitroblue tetrazolium (NBT), 2, 2-diphenyl-1-picryl-hydrazyl-hydrate (DPPH), diphenyleneiodonium chloride (DPI), agarose, ornithine, putrescine, spermidine, 2', 7'-dichlorodihydrofluorescein diacetate $\left(\mathrm{H}_{2} \mathrm{DCFDA}\right)$, Sodium antimony Gluconate (SAG), Miltefosine were obtained from Sigma Aldrich. 7, 8 dihydroxyflavone (DHF) was purchased from Tokyo Chemical Industry (TCl). Kits for RNA isolation, genomic DNA isolation and cDNA synthesis were purchased from Agilent, Qiagen, and BioRad respectively. Other routine chemicals of analytical grade were from Merck, India. Raw 264.1 and THP1 cell lines were procured from National Centre for Cell Science (NCCS) - Pune. All the solvents except ethanol were from HiMedia, India. UV-visible spectra were recorded with a Shimadzu UV-240, Hitachi U-3200 spectrometer with a path length of $1 \mathrm{~cm}$. FT-IR spectra were recorded with a PerkinElmer Inc. (Waltham, MA, USA) Spectrum 400 spectrometer. Zeta potential was analyzed using Beckman Coulter (Brea, CA, USA) Delsa nano submicron particle size and zeta potential analyzer. TEM images were taken with a (JEOL-JEM 2010, Tokyo, Japan) transmission electron microscope (TEM) operated at $120 \mathrm{keV}$.

\section{Cell cultures}

LD promastigotes were cultured in medium 199 supplemented with FBS (10\%) and penicillin/ streptomycin (1\%). Mouse macrophage-specific cell line Raw 264.7 cells were cultured in growth medium RPMI-1640 supplemented with FBS (10\%) and penicillin/ streptomycin (1\%) in the presence of $5 \% \mathrm{CO}_{2}$ at $37^{\circ} \mathrm{C}$. The AmB-resistant clinical isolate of LD was a kind gift from Dr. Syamol Roy, NIPER-Kolkata. A clinical isolate of SAG-Resistant strain was a gift from Dr. Mitali Chatterjee, Institute of Post Graduate Medical Education and Research - Kolkata.

\section{Synthesis and conjugation of GNP with DHF}

Reactions were done at room temperature unless mentioned. Chemical synthesis of GNP using sodiumcitrate was done as described previously [3]. Synthesis of citrate reduced GNP (c-GNP) was confirmed by measuring absorbance at $530 \mathrm{~nm}$. Green synthesis of GNPs was done by DHF $(0.8 \mathrm{mM})$ solution. Due to the low solubility of DHF in the water of neutral $\mathrm{pH}$, the stock solution of DHF was prepared at pH 9.0. 4 
$\mathrm{ml}$ DHF solution was added dropwise to $20 \mathrm{~mL}$ of $\mathrm{HAuCl}_{4}(0.5 \mathrm{mM})$ and stirred for $20 \mathrm{~min}$ at room temperature followed by heating at $80-90^{\circ} \mathrm{C}$. Besides, the color of the reaction mixture changed from pale yellow to wine red. The reaction was continued at room temperature for another $30 \mathrm{~min}$. The resulting mixture was centrifuged at $12000 \mathrm{~g}$ for $15 \mathrm{~min}$, washed with DDW of pH 9.0 for five times. The pellet was re-suspended in $2 \mathrm{ml}$ water of $\mathrm{pH} 8.0$ at $4^{\circ} \mathrm{C}$ for further use.

\section{Characterization of c-GNP and DHF-GNP nanoparticles}

NPs were analyzed by UV-Visible spectrophotometer, DLS, Fourier transform IR (FT-IR) and TEM studies. Hydrodynamic diameter, polydispersity index (PDI) and zeta potential were determined on a Beckman Coulter's Delsa nano submicron particle size and zeta potential analyzer (Brea, CA, USA) as per standard procedures. For FT-IR analysis, purified nanoparticles (DHF-GNP) were scanned over a range of 4000 to $400 \mathrm{~cm}^{-1}$ in the Perkin Elmer Spectrum 400 spectrometer. Furthermore, NPs were processed and analyzed by TEM (JEOL-JEM 2010, Tokyo, Japan) analysis for the determination of their shape using standard procedures [4]. For powdered X-ray diffraction (pXRD) analysis, about $40 \mathrm{ml}$ DHF-GNP sample was dried in a vacuum evaporator. The powdered sample of DHF-GNP was then analyzed in a Rigaku TTRX-III diffractometer using a Cu-Ka $(\lambda=1.54 \AA)$ as the $X$-ray source. The scan range was $10-80^{\circ}$ at a scan speed of $0.02^{\circ} / \mathrm{sec}$ and step size $0.02^{\circ}$.

\section{In vitro assay against promastigotes}

L. donovani (MHOM/IN/1983/AG83) promastigotes were cultured as described [3]. Log phase cells $\left(1 \times 10^{6} / \mathrm{ml}\right)$ were treated with c-GNP $(5-160 \mu \mathrm{M})$, DHF $(5-320 \mu \mathrm{M})$ and DHF-GNP $(5-80 \mu \mathrm{M})$ for 3-4 days and cell viability was measured by Trypan blue exclusion \& 3-(4,5-dimethylthiazol-2-yl)-2,5diphenyltetrazolium bromide (MTT) reduction method after every $24 \mathrm{~h}$ using standard procedures. After $48 \mathrm{~h}$, the concentration of the drug which showed $50 \%$ killing of the parasite was considered $\mathrm{IC}_{50}$ for that drug. Drug-treated cells were pre-incubated with $\mathrm{N}$-acetyl L-cysteine (NAC, $1 \mathrm{mM}$ ) when required [3].

\section{Ex vivo assay against amastigotes}

RAW 264.1 cells were maintained in RPMI-1640 medium and infected with promastigotes as described [3]. Parasite-infected macrophages, grown for another $24 \mathrm{~h}$, were treated with varying concentrations of DHF (5-160 $\mu \mathrm{M})$, DHF-GNP $(5-160 \mu \mathrm{M})$ and c-GNP $(5-80 \mu \mathrm{M})$ and chamber slides were washed and supplemented with fresh medium and kept in a $\mathrm{CO}_{2}$ incubator for another $12 \mathrm{~h}$. Untreated parasiteinfected macrophages were used as control. Amastigotes from 100 macrophage nuclei per well were counted, at least, under the oil immersion objective of a light microscope (Nikon Eclipse TS100, Japan) after methanol fixation and Giemsa staining of the slides. $\mathrm{IC}_{50}$ for the drug was determined by standard protocol after 48 hours.

\section{Cytotoxicity assays}


Cytotoxicity was measured by MTT assay, against human THP-1 cell lines. Briefly, THP-1 cells were cultured with RPMI-1640 medium in 6 well plates (2×10\%/well) and treated with c-GNP, DHF-GNP and DHF at 5-1000 $\mu \mathrm{M}$ concentration for $48 \mathrm{~h}$ and cell viability was measured as described [3].

\section{Determination of ROS in promastigotes}

The generation of reactive oxygen species upon drug treatment was measured by $\mathrm{H}_{2}$ DCFDA mediated fluorimetric assay [33]. The Promastigotes ( $1 \times 10^{6}$ cells in each assay) were treated with $5 \mu \mathrm{M} c-\mathrm{GNP}, 40-$ $280 \mu \mathrm{M}$ DHF and $40-280 \mu \mathrm{M}$ of DHF-GNP for $12 \mathrm{~h}$ and accumulated ROS was measured by $\mathrm{H}_{2}$ DCFDA for untreated cells [34].

\section{Determination of RNS in amastigotes}

Reactive nitrogen species in amastigotes were measured with Griess after treatment with different doses of DHF $(40-160 \mu \mathrm{M})$, DHF-GNP $(20-80 \mu \mathrm{M})$ and c-GNP $(2.5-10 \mu \mathrm{M})$ as described earlier. Macrophages were pretreated with $\mathrm{DPI}(0.1 \mathrm{mM})$ when required [34].

\section{Determination of uptake by AAS}

RAW264.1 cells $\left(3 \times 10^{6}\right)$ were plated on a 24-well plate and incubated under $5 \% \mathrm{CO}_{2}$ at $37^{\circ} \mathrm{C}$ overnight. Cell suspensions were exposed to $10 \mu \mathrm{M}$ and $20 \mu \mathrm{M}$ of c-GNP and $20 \mu \mathrm{M}$ and $40 \mu \mathrm{M}$ of DHF-GNP at the time of plating for $6 \mathrm{~h}$ and $12 \mathrm{~h}$. After $6 \mathrm{~h}$ incubation, the cells were washed with PBS thrice and were subsequently digested for the detection of gold by AAS $[35,36]$. The cell samples were mixed with concentrated nitric acid and $30 \% \mathrm{H}_{2} \mathrm{O}_{2}$ in a ratio of (8:1) to make the final volume of the sample mixture to $5 \mathrm{~mL}$ in an Xpress Teflon vessel. They were then digested in a CEM MARS 5 microwave digestion system at $160{ }^{\circ} \mathrm{C}$ and a power level of $400 \mathrm{~W}, 100 \%$ efficiency, for 20 min of ramping and $15 \mathrm{~min}$ of holding time. After digestion, each of the digested sample volumes make-up to $5 \mathrm{~mL}$ each. A standard graph was plotted with different concentration (blank, 10, 20, and $30 \mu \mathrm{g} / \mathrm{L}$ ) of Au sample in $0.4 \% \mathrm{HCL}$ solution [37], and atomic absorption spectra were taken at $242.8 \mathrm{~nm}$ using a graphite tube atomizer (Zeeman Atomic Absorption Spectrophotometer, AA240Z) and a hollow cathode Au(coded)-lamp (Agilent Technologies India Pvt. Ltd). Sample data were collected successively and analyzed using SeptraAA 5.0 software.[38].

\section{Field emission scanning electron microscopy (FE-SEM)}

The treated (c-GNP and DHF-GNP) and untreated samples were washed with PBS and water three times. Then, the cells were suspended in $0.1 \mathrm{M}$ sodium cacodylate buffer, $\mathrm{pH} 7.4$ containing $2 \%$ formaldehyde and $2.5 \%$ glutaraldehyde, and left for $2 \mathrm{~h}$. The chemically fixed cells were washed with water three times. The cells were now dehydrated by using ethanol at gradient concentration $(50 \% \mathrm{EtOH} 5 \mathrm{~min}, 70 \% \mathrm{EtOH} 5$ min, $95 \% \mathrm{EtOH} 10 \mathrm{~min}, 100 \% \mathrm{EtOH} 10 \mathrm{~min}$ ). $10 \mu \mathrm{L}$ of the dehydrated samples were dropped cast on silicon wafers and dried in a vacuum desiccator. The samples were sputter-coated with gold and finally 
observed within a field emission scanning electron microscope (FE-SEM) with a Zeiss GeminiSEM 500." [39].

\section{DPPH assay}

DPPH assay was used to evaluate antioxidant activity using a standard protocol [40]. Due to a strong absorption band at $520 \mathrm{~nm}$, the DPPH radical has a deep violet colour in the solution, and it becomes colourless or pale yellow when neutralized. This colour change can be detected and measured by spectrophotometry. The use of the DPPH assay provides a way to evaluate antioxidants. $120 \mu$ l of $0.1 \mathrm{mM}$ DPPH solution was added to $1.5 \mathrm{ml}$ of methanol (98\%). 5-80 $\mu \mathrm{M}$ each of DHF and DHF-GNP was incubated with $100 \mu \mathrm{l}$ of prepared stock of DPPH solution. The mixtures were shaken and allowed to stand at room temperature for 30 minutes. Then the absorbance was measured at $517 \mathrm{~nm}$ using a UVVIS spectrophotometer.

\section{Arginase assay}

To evaluate the effect of DHF and NPs on LD arginase, an arginase assay was performed as described previously [41]. Promastigotes were treated with $\mathrm{IC}_{50}$ doses of c-GNP, DHF and DHF-GNP and cell lysates were prepared by resuspending harvested cells in lysis buffer with $0.1 \%$ of Triton X-100 [42]. $25 \mu$ l of cell lysates were solubilized with $25 \mu \mathrm{l}$ of lysis buffer containing: $0.1 \%$ Triton $x-100,10 \mathrm{mM} \mathrm{MnCl}_{2}$ and $50 \mathrm{mM}$ Tris- $\mathrm{HCl}\left(\mathrm{pH} \mathrm{7.5)}\right.$. Arginase was activated by heating for $7 \mathrm{~min}$ at $56^{\circ} \mathrm{C}$. L-arginine hydrolysis was done by incubating the activated lysates with $50 \mu \mathrm{l}$ of $\mathrm{L}$-arginine $\left(\mathrm{pH} \mathrm{9.7)} \mathrm{at} 37^{\circ} \mathrm{C}\right.$ for $60 \mathrm{~min}$. The reaction was stopped by the addition of $400 \mu \mathrm{l}$ acid solution $\left(\mathrm{H}_{2} \mathrm{SO}_{4}(96 \%) / \mathrm{H}_{3} \mathrm{PO}_{4}(85 \%) / \mathrm{H}_{2} \mathrm{O}(1: 3: 7, \mathrm{v} / \mathrm{v} / \mathrm{v})\right.$. Then 20 $\mu \mathrm{l}$ of $9 \%$ ISPF (a-isonitrosopropiophenone) (dissolved in $100 \%$ ethanol) was added, heated at $100^{\circ} \mathrm{C}$ for $45 \mathrm{~min}$ and spectrophotometric reading was taken at $540 \mathrm{~nm}$ [43]. Assay without L-arginine was used as a negative control.

\section{Supplementation assay}

To evaluate the involvement of enzymes of polyamine biosynthesis pathway in parasite death and survival, the culture medium was preincubated with $1 \mathrm{mM}$ arginine, ornithine, putrescine and spermidine before treatment with $140 \mu \mathrm{M}$ of DHF and $40 \mu \mathrm{M}$ of DHF-GNP [44]. Cells were treated with various drug concentrations and cell viability was estimated after every 24 hours for 3 days by both trypan blue exclusion assay and MTT assay. The percentage of survival was calculated using drug-treated cells as control.

\section{Superoxide dismutase (SOD) assay}

Promastigotes $\left(5 \times 10^{6}\right.$ cells $\left./ \mathrm{ml}\right)$ were treated with DHF $(120-240 \mu \mathrm{M})$, DHF-GNP $(40-80 \mu \mathrm{M})$ and c-GNP $(20$ $\mu \mathrm{M})$ for 12 hours and then harvested. Cells were lysed and the SOD enzyme activity assay was performed as described [3]. AmB $(0.2 \mu \mathrm{M})$-treated parasites are used as a positive control. 


\section{Ascorbate peroxidase (APx) assay}

Log phase promastigotes were treated with $120-240 \mu \mathrm{M}$ DHF, $40-80 \mu \mathrm{M}$ of DHF-GNP and $20 \mu \mathrm{M}$ of c-GNP and allowed to incubate for 12 hours. After incubation, the cells were harvested and washed with 1X PBS. A cell lysate was prepared by resuspending harvested cells in lysis buffer with $0.1 \%$ of Triton X-100. An equal volume of cell lysate from each treated sample was used for the APx assay. The assay was started by adding $50 \mathrm{mM}$ potassium phosphate buffer ( $\mathrm{pH} 7.0), 0.5 \mathrm{mM}$ ascorbic acid, $0.1 \mathrm{mM}$ EDTA, $0.1 \mathrm{mM}$ $\mathrm{H}_{2} \mathrm{O}_{2}$, cell lysate and adjusting the volume up to $2 \mathrm{ml}$ with double distilled water. The reaction was allowed to run for $5 \mathrm{~min}$ at $25^{\circ} \mathrm{C}$. APx (Ascorbate peroxidase) activity was assayed by recording the decrease in optical density at $290 \mathrm{~nm}$. The activity of the enzyme was determined in terms of $\mu \mathrm{mol}$ per min [45]. $1 \mu \mathrm{M}$ miltefosine-treated cells were used as a positive control.

\section{Isolation of total RNA}

To study the role of genes in DHF and DHF-GNP treated parasites, total RNA was isolated after drug treatment followed by semi-quantitative PCR. For isolation of RNA parasites $\left(5 \times 10^{6}\right.$ cells $/$ well) were treated with $10 \mu \mathrm{M}$ c-GNP, $140 \mu \mathrm{M}$ DHF, and $40 \mu \mathrm{M}$ DHF-GNP for 6 hours. Treated cells were centrifuged at $4200 \mathrm{~g}$ for 10 minutes, washed thrice with PBS, and then total RNA was isolated by the addition of TRIZOL solution. Pellet of RNA was air-dried, re-suspended in $100 \mu \mathrm{L}$ of RNase-free water, and treated with DNase I $(1 \mathrm{U} / \mu \mathrm{l})$ at $37^{\circ} \mathrm{C}$ for 30 minutes. Digested RNA was loaded on RNeasy Mini Kit columns, and RNA was eluted in $30 \mu \mathrm{l}$ of RNase-free water. RNA quality was checked by gel electrophoresis and quantified by Nanodrop spectrophotometer (Thermo scientific, Nanodrop 2000, USA). For isolation of RNA from macrophage-infected parasites, RAW 264.1 cells $\left(1 \times 10^{6} /\right.$ well) were grown in a 6 well plate and infected with $1 \times 10^{7}$ parasites for 12 hours, non-phagocytic cells were washed out; a fresh medium was added and then incubated further for 12 hours. Parasite-infected macrophages were treated with c-GNP $(20 \mu \mathrm{M})$, DHF $(40 \mu \mathrm{M})$, and DHF-GNP $(22 \mu \mathrm{M})$ for 6 hours, and then RNA was isolated from the cell pellet as described above. The isolated RNA was converted into cDNA with the help of a BioRad cDNA synthesis kit following the manufacturer's protocol.

\section{Semi-quantitative PCR for gene expression studies}

Reverse transcription was performed using $1 \mu \mathrm{g}$ of total RNA by cDNA synthesis kit (Roche, USA) according to the manufacturer's instruction. The synthesized cDNAs (from RNA of promastigotes) were amplified by PCR (primer detail is mentioned in Supplementary Table 1) for specific genes viz. arginase, ornithine decarboxylase (ODC), trypanothione reductase (TryR), spermidine synthase (SPD), trypanothione synthase (TryS), multidrug transporter 1 (MDR1), amino acid permease 3 (AAP3), glyceraldehyde 3 phosphate dehydrogenase (GAPDH) and a-tubulin. The synthesized cDNAs (from RNA of amastigote infected macrophages) were amplified by PCR for genes viz. IFN-y, inducible nitric oxide synthase (iNOS), IL-10. GAPDH was used as a loading control for both promastigotes and macrophage models. For the promastigote model a-tubulin is also used as an additional loading control. The PCR mixture $(25 \mu \mathrm{l})$ contains $0.6-0.8 \mu \mathrm{M}$ of forward and reverse primer, $0.5 \mathrm{mM}$ of each dNTP, $2 \mathrm{mM} \mathrm{MgCl}, 0.5$ 
$\mu \mathrm{g}$ of synthesized cDNA and $1 \mu \mathrm{l}$ Taq polymerase. The sequence of PCR primers, annealing temperature, and the size of PCR products were shown in the supplementary Table1. The PCR was done for 25 cycles, where each cycle had denaturation at $95^{\circ} \mathrm{C}$ for 45 seconds, annealing (ranging from $55-62^{\circ} \mathrm{C}$ ) for 30 seconds, and extension at $72^{\circ} \mathrm{C}$ for 45 seconds. Samples were preheated at $95^{\circ} \mathrm{C}$ for 3 minutes before PCR. The products were run on $1.5 \%$ agarose gel, stained with ethidium bromide $(0.5 \mu \mathrm{g} / \mathrm{ml})$, and finally documented and quantified using the gel documentation system and associated Gene-tool software (Syngene, USA).

\section{Statistical analysis}

The statistical analysis was done by one-way and two-way ANOVA using Graphpad Prism software (version 5.00; Graphpad Software Inc., La Jolla, CA, USA). The results were measured as mean \pm SD of at least three independent experiments. The results were shown as approximate mean values. Differences between group data were considered statistically significant and highly significant when $P<0.05$ and $P<0.001$, respectively.

\section{Results And Discussion}

Leishmaniasis affects around 12 million people in 98 countries of mostly the developing world. It is transmitted by sandflies (Phlebotomus spp.), a small biting mosquito, which breeds in moist soil, forest areas, or caves and feed from infected animal reservoir hosts or humans [46]. It comprises a complex group of diseases ranging from self-healing cutaneous lesions $(\mathrm{CL})$ to severe and systemic visceral leishmaniasis (VL). VL (also known as kala-azar) is a parasitic disease affecting an estimated 500,000 new cases per year mostly in the Indian subcontinent and East Africa [47]. Conventional chemotherapy which primarily uses Amphotericin B (AmB) as a deoxycholate formulation (fungizone) was effective but came with severe nephrotoxicity [48]. Application of liposomal AmB reduces the problem of toxicity [49] but comes with a high cost in treatment [43,44]. Different natural compounds from plants such as Flavonoids, Polyphenols, Chalcones, Lignins, etc. were reported as antiparasitic agents with the possible mechanism of action [50,51]. Although flavonoids/ polyphenols are less cytotoxic than standard chemotherapeutic agents their use was severely restricted due to poor water solubility and less bioavailability [52]. Very high first-pass metabolism involving phase II conjugation (i.e., glucuronidation and/or sulfonation) of polyphenols is the leading cause of their poor bioavailabilities [53]. Flavonoid functionalized NPs were reported to increase the bioavailability of flavonoids with a consequent increase in antileishmanial efficacy than standard chemotherapeutic agents against sensitive and drug-resistant strains [54]. GNPs synthesized from Flavonoids were found to be non-cytotoxic with improved macrophage delivery and antileishmanial efficacy [55]. In this work, we have used DHF as a reducing and capping agent for the green synthesis of GNP. DHF was earlier reported in an animal model of VL but was found to be ineffective [28]. Till then, no further study was reported for DHF against parasitic diseases although DHF was extensively used in various neurological diseases with safety and efficacy [30,56]. Due to poor solubility, DHF was solubilized in the water of $\mathrm{pH} 9.0$ and then used for the synthesis of GNP. The characteristic peak at $\sim 530 \mathrm{~nm}$ in UV-Visible spectroscopy, along with a change from colourless to a 
red wine colour confirms the reduction and synthesis of GNP. Further, a separate peak at $350 \mathrm{~nm}$, which comes from DHF, confirms the association of DHF in DHF-GNP (Fig. 1A). The weak peak of the oxidized form of gold $\left(\mathrm{HAuCl}_{4}\right)$ appears at $410 \mathrm{~nm}$ but only at a concentration of $30 \mathrm{mM}$. This peak disappears after the reduction and synthesis of GNP, which gives an intense peak at $530 \mathrm{~nm}$, even at $3 \mathrm{mM}$ concentration. It indicates the reduction of $\mathrm{Au}^{3+}$ to $\mathrm{Au}^{0}$ in presence of DHF. Measurement of concentration in UV-visible spectroscopy for unbound and washed DHF showed conjugation efficiency of 8-10\% DHF in DHF-GNP. Therefore, $40 \mu \mathrm{M}$ gold is associated with $1.33 \mu \mathrm{M}$ DHF in DHF-GNP. From here on, the given concentration of DHF-GNP in each assay will indicate the concentration of GNP in it. The synthesized GNP is stable at room temperature for 6 months with no change in biological activity. In FT-IR analysis, a broadened $\mathrm{O}-\mathrm{H}$ stretch at $~ 3000 \mathrm{~cm}^{-1}$ was observed due to $\mathrm{H}$-bonding, which is reduced in DHF-GNP and shifted towards $\sim 3400 \mathrm{~cm}^{-1}$. This is, possibly, due to the association of $-\mathrm{OH}$ group of catechol ring of DHF in DHF-GNP (Fig. 1B). Further, numerous bending vibrations of DHF, which were seen in the fingerprint region of $600-1400 \mathrm{~cm}^{-1}$, are reduced in DHF-GNP due to non-covalent attachment in GNP (Fig. 1B). DLS studies revealed the diameter of DHF-GNP as $35 \pm 7.4 \mathrm{~nm}$ with PDI $0.19 \pm 0.01$, which indicates well-nigh uniformity in the particle size. The notable high value of the zeta potential of DHFGNP (-34.1 mV) indicates the excellent stability of our synthesized nanoparticles (Supplementary Fig. 1). The DLS studies and TEM analysis of c-GNP were also carried out to ascertain its size and shape (Supplementary Fig. 8A and 8B) which is consistent with previous data [3]. Further, TEM analysis of DHFGNP confirms the uniform and spherical size of NPs with a diameter of $18.5 \pm 2.4 \mathrm{~nm}$ (Fig. 2A and 2B). The difference in diameter of the c-GNP and DHF-GNP from DLS and TEM analysis was ascribed to differences in DLS and TEM measurement techniques. Powdered X-Ray Diffraction ( $p X R D$ ) measurement revealed Bragg's diffraction at $38.2^{\circ}, 47.7^{\circ}, 65.3^{\circ}$, and $77.1^{\circ}$ which were attributed to (111), (200), (220), and (311) sets of lattice planes reflecting the face-centered cubic structure of metallic gold. The pXRD pattern thus confirms the crystalline nature of GNP in DHF-GNP (Fig. 2C).

To compare the biological efficacy and cytotoxicity, we prepared citrate-reduced GNP (c-GNP) to study in parallel with DHF-GNP [3]. DHF showed $\mathrm{IC}_{50}$ of $\sim 140 \mu \mathrm{M}(\sim 36 \mu \mathrm{g} / \mathrm{ml})$ against LD promastigotes

(Fig. 3A). This value is higher than what is reported earlier for in vitro studies against axenic amastigotes of LD $\left(\sim 1.7 \mu \mathrm{g} / \mathrm{ml}\right.$, [28]. For DHF-GNP and c-GNP the IC ${ }_{50}$ is $\sim 40 \mu \mathrm{M}$ and $\sim 10 \mu \mathrm{M}$ respectively. Therefore, DHF-GNP is less effective than c-GNP against LD. However, DHF-GNP is more efficient than DHF alone, considering $~ 1.33 \mu \mathrm{M}$ DHF is associated with DHF-GNP ( $P<0.001$, Fig. 3A). Efficacy of DHF-GNP was increased in ex vivo amastigote model where $\mathrm{IC}_{50}$ is reduced to $\sim 22 \mu \mathrm{M}$ compared to $\sim 40 \mu \mathrm{M}$ in the promastigotes model $\left(\mathrm{P}<0.001\right.$, Fig. 3B). For DHF we, also see a decrease in $\mathrm{IC}_{50}$ against amastigotes than promastigotes $(\sim 40 \mu \mathrm{M}$ vs. $\sim 140 \mu \mathrm{M})$. A dose-dependent steep decrease in parasite survival was observed for DHF-GNP than in DHF-alone (Fig. 3B). The $72 \mathrm{~h}$ data on dose response curve shows that $\mathrm{IC}_{50}$ of DHF and DHF-GNP is $\sim 60 \mu \mathrm{M}$ and $\sim 18 \mu \mathrm{M}$, respectively against promastigotes (Supplementary Fig. 2A). Against amastigotes, after $72 \mathrm{~h}$ the $\mathrm{IC}_{50}$ of DHF and DHF-GNP is $\sim 25 \mu \mathrm{M}$ and $\sim 13 \mu \mathrm{M}$ (Supplementary Fig. 2B). This data correlates well with early published reports on fast macrophage uptake of flavonoid-functionalized GNPs in the VL model [4]. It suggests that there is a possible 
advantage of GNP-based drug delivery in VL since the parasite primarily infects the macrophages of the liver and spleen. Again, C-GNP was very effective against amastigotes with an $\mathrm{IC}_{50}$ of $\sim 10 \mu \mathrm{M}$, after $48 \mathrm{~h}$ (Fig. 3B) as we observed in our previous studies [3].

Flavonoid and its derivatives are well established for their efficacy against drug-resistant LD due to inhibition of multidrug transporter 1 (MDR1), thereby accumulating high intracellular drug concentration $[54,57]$. A similar trend was observed for DHF and DHF-GNP against AmB- resistant and SAG-resistant LD as compared to sensitive strains. The $\mathrm{IC}_{50}$ for DHF and DHF-GNP is $\sim 150 \mu \mathrm{M}$ and $\sim 40 \mu \mathrm{M}$, respectively, against the AmB-resistant parasite (Fig. 3C). Against SAG-resistant parasite, the $\mathrm{IC}_{50}$ for DHF and DHFGNP is $\sim 160 \mu \mathrm{M}$ and $\sim 35 \mu \mathrm{M}$ respectively (Fig. 3D) and almost similar to sensitive strains. IC ${ }_{50}$ for AmB against AmB-resistant strain was increased $~ 5.8$ fold, whereas, for SAG, the $\mathrm{IC}_{50}$ was increased $\sim 4.2$ fold, which is consistent with the previously reported data confirming the drug-resistance associated with these clinically isolated strains $[34,58]$.

Cytotoxicity studies on THP- 1 cells show that $\mathrm{CC}_{50}$ (cytotoxic concentration for $50 \%$ viability of THP-1) values of c-GNP are $25 \mu \mathrm{M}$. However, with DHF-GNP even with $1000 \mu \mathrm{M}$, the cell viability is $~ 70 \%$ (Fig. 4C). Also, at $160 \mu \mathrm{M}$ concentrations, the survival of c-GNP and DHF-GNP treated THP-1 cells was $24 \%$ and $\sim 80 \%$, respectively ( $P<0.001$, Fig. $4 \mathrm{C}$ ). Therefore, the synthesis of GNP with DHF, instead of, sodium citrate increases the biocompatibility of GNP significantly without compromising the biological efficacy.

Studies with DHF and other flavonoids of similar structures have shown that the arginase of Leishmania amazonensis species is inhibited by these flavonoids, whereas the mammalian counterpart is uninhibited [59]. Arginase, the first enzyme in the polyamine biosynthesis pathway, converts L-arginine to ornithine. Conversion of ornithine to putrescine by ornithine decarboxylase (ODC) is the rate-limiting step in polyamine biosynthesis [44]. DHF and DHF-GNP treated parasites show a $\sim 2.1$ and $~ 4.4$ fold decrease in arginase expression, respectively, as measured by semi-quantitative PCR (Fig. 4A). Parasites treated under the same conditions do not show any significant change in the gene expression of ODC, spermidine synthase (Spd) and S-adenosylmethionine decarboxylase (AdoMetDC), which are downstream enzymes in the polyamine biosynthesis pathway. Further, we studied gene expression level after using $\mathrm{IC}_{50}$ dose for $24 \mathrm{~h}$ (Figure S6A) and twice of $\mathrm{IC}_{50}$ dose for $8 \mathrm{~h}$ (Figure S6B) on L. donovani cells. In all these studies we found a consistent and significant decrease in gene expression of arginase and MDR-1. Consequently, arginase assay with DHF and DHF-GNP-treated cell lysates show a gradual decrease in arginase activity in a time-course study. There were $20 \%, \sim 45 \%$, and $65 \%$ inhibition of arginase activity after 24,48 , and $72 \mathrm{~h}$ of DHF treatment (Fig. 5A). For DHF-GNP the inhibition was $~ 31 \%$, $\sim 63 \%$, and $\sim 83 \%(\mathrm{P}<0.001$, Fig. $5 \mathrm{~A})$ under similar conditions. Therefore, DHF-GNP is a more potent inhibitor of arginase than DHF alone. In short, gene expression and enzyme studies prove that inhibition of arginase is the possible cause of parasite death in vitro. This observation was further confirmed by supplementation with ornithine, the product of arginase enzyme, in DHF, and DHF-GNP treated parasites. Preincubation of DHF and NP-treated cells with $1 \mathrm{mM}$ ornithine increases cell survival from $~ 49 \%$ to 
$82 \%$ for DHF and $\sim 45 \%$ to 92\% for DHF-GNP after $48 \mathrm{~h}$ ( $\mathrm{P}<0.001$, Fig. $5 \mathrm{~B}$ ). Following a similar trend, 1 $\mathrm{mM}$ ornithine supplementation increases cell survival from $\sim 31 \%$ to $~ 72 \%$ for DHF and $\sim 23 \%$ to $~ 85 \%$ for DHF-GNP after $72 \mathrm{~h}(\mathrm{P}<0.001$, Fig. $5 \mathrm{C})$. Therefore, parasite survival can be simply increased by supplementation of ornithine, the product of arginase enzyme, in the growth medium. This indicates inhibition of arginase as the primary reason for DHF and DHF-GNP induced cell death in vitro. This observation was further supported by an increase in cell survival with increasing doses of ornithine. Preincubation of DHF-treated cells with $0.05,0.25$, and $1 \mathrm{mM}$ of ornithine increases parasite survival from $\sim 31 \%$ to $\sim 47 \%, \sim 63 \%$, and $\sim 64 \%$ respectively after $72 \mathrm{~h}$ (Fig. 5D). For DHF-GNP treated cells under similar conditions, the parasite survival increases from $\sim 24 \%$ to $~ 55 \%, ~ 82 \%$, and $~ 86 \%$ (P< 0.001 , Fig. 5D). These data indicate the importance of ornithine, the product of arginase, and consequently, the role of arginase inhibition in DHF and DHF-GNP induced cell death. Also, these results show DHF-GNP is more potent inhibitor of arginase than DHF alone.

Supplementation with putrescine, the substrate for ODC, provides partial recovery in cell survival for DHF after $48 \mathrm{~h}(\sim 49 \%$ to $\sim 59 \%)$ and $72 \mathrm{~h}(\sim 31 \%$ to $\sim 50 \%)$. For DHF-GNP treated cells, the recovery with putrescine was $\sim 45 \%$ to $\sim 60 \%$ after $48 \mathrm{~h}$ and $\sim 22 \%$ to $\sim 52 \%$ after $72 \mathrm{~h}$ (Fig. $5 \mathrm{~A}$ and $5 \mathrm{~B}$ ). This indicates a possible secondary response involving inhibition of ODC in parasite death since arginase and ODC are the first two enzymes in the polyamine biosynthesis pathway. Supplementation with spermidine, the product of ODC, does not provide any significant change in parasite survival under similar conditions. Since the growth medium is already enriched with $L$-arginine $(70 \mathrm{~g} / \mathrm{L})$, supplementation of arginine does not cause any significant change in survival after DHF and DHF-GNP treatment (Fig. 5B and 5C) as expected.

The enzymes Trypanathione synthase (TryR) and reductase (TryR) are involved in the biosynthesis of trypanothione (major thiol of Leishmania along with glutathione) and maintain the reduced status of LD under oxidative stress along with other two enzymes Superoxide dismutase (SOD) and Ascorbate peroxidase (APx). Gene expression study showed very little change in the mRNA level of SOD, APx, and Try after DHF and DHF-GNP treatment compared to untreated cells (Fig. 4A). In parallel, SOD and APx assay with parasite cell lysate do not show any significant change in activity either (Supplementary Fig. 5A or 5B). However, substantial inhibition for SOD with AmB [3] and APx with miltefosine [45] was observed under similar conditions. Investigation of DHF-GNP and c-GNP treated Leishmania cells by FESEM analysis does not show any significant damage to the membrane of the parasite (Fig. 6A, 6B and $6 \mathrm{C}$ ) although the flagella disappeared due to treatment indicating cell death. FE-SEM studies further confirm that DHF-GNP kills the parasite through a mechanism that is independent of membrane damage further reaffirming the role of arginase inhibition as a main cause of death. Furthermore, the uptake of cGNP and DHF-GNP by RAW 264.1 cells was also investigated through AAS. The uptake of both c-GNP and DHF-GNP increased in a dose- and time-dependent manner (Fig. 6D). In the case of c-GNP treated cells, the gold uptake increased from $0.7 \mathrm{ng} / 10^{6}$ cells to $1.37 \mathrm{ng} / 10^{6}$ cells whereas, in DHF-GNP treated cells the gold uptake increased from $0.457 \mathrm{ng} / 10^{6}$ cells to $0.927 \mathrm{ng} / 10^{6}$ cells after $12 \mathrm{~h}$. This level of uptake was very consistent with the GNP uptake of macrophages done elsewhere [60]. Therefore, 
increased inhibition of arginase activity and consequent killing of parasites is well supported by increased DHF-GNP uptake by macrophages. Flavonoids contain both antioxidant and prooxidant properties, and the switch from one form to another depends on the positions of hydroxyl groups and the redox status of chelated metal [61]. The antioxidant property, as measured by DPPH scavenging assay, was abolished entirely in DHF-GNP, whereas DHF showed a dose-dependent increase (Supplementary Fig. 4A). Conjugation of phenolic-OH with GNP may be the reason for the loss of antioxidant activity. In parallel, we found slightly increased prooxidant activity of DHF-GNP compared to DHF as measured by ROS (Supplementary Fig. 4B). Overall, gene expression and enzyme-based studies prove that oxidative stress is not involved in DHF and DHF-GNP mediated parasite death in vitro. Decreased expression of MDR1 ( 2.1 and $~ 3.4$ fold reduction in DHF and DHF-GNP treated cells compared to untreated cells, Fig. 4A) further confirms the role of these transporters, which is inhibited by many flavonoids [57]. We have not found any change in gene expression of amino acid permease 3 (AAP3), known for L-arginine transport in LD [62], in DHF and DHF-GNP treated parasites (Fig. 4A).

Oxidation of L-arginine by host inducible nitric oxide synthase (iNOS) produces nitric oxide (NO), which contributes to parasite killing. In contrast, hydrolysis of L-arginine by host arginase blocks NO generation and provides polyamines supporting parasite proliferation $[63,64]$. NO is a potent cytotoxin involved in the clearance or inhibition of intracellular pathogens like Leishmania. We found a dose-dependent increase of reactive nitrogen species (RNS) after treatment with DHF and DHF-GNP on macrophages infected with LD amastigotes. There was a $~ 2.7$ and $\sim 3.2$ fold increase in NO production after DHF and DHF-GNP treatment (Supplementary Fig. 3). Pre-treatment of cells with $1 \mathrm{mM} \mathrm{DPI}$, an inhibitor of iNOS, abolishes NO production indicating the role of increased iNOS activity for the death of amastigotes. This is further confirmed by an increased mRNA level of iNOS for DHF and DHF-GNP treated cells $(\sim 2.1$ and $\sim$ 3.5 fold, respectively, Fig. 4B) compared to the untreated control. Leishmania-infected macrophages generally activate $T_{h} 1$ cytokines and down-regulate $T_{h} 2$ cytokine to produce NO via iNOS, thereby facilitating parasite killing [65]. We found a $\sim 2.8$ and $\sim 3.7$ fold increase in mRNA level of IFN- $\gamma, a T_{h} 1$ cytokine, for DHF and DHF-GNP treated cells compared to untreated control (Fig. 4B). In contrast, there was a $\sim 1.2$ and $\sim 2.3$ fold decrease in mRNA level of IL-10, a $T_{h} 2$ cytokine, under similar conditions. Additionally, when the amastigotes are treated with twice the $\mathrm{IC}_{50}$ dose for $8 \mathrm{~h}$, a similar trend is followed for expression of IFN-y, iNOS and IL-10 (supplementary Figure S7). Therefore, gene expression data correlates well with an increased $T_{h} 1 v$ s. decreased $T_{h} 2$ response leading to increased host iNOS activity and consequent parasite killing. In short, DHF-GNP kills promastigotes by inhibiting arginase and MDR1 whereas it activates host iNOS to kill the amastigotes (Fig. 7).

\section{Conclusion}

The low bioavailability of flavonoids has restricted their use in animal studies and future drug development. Flavonoids were chemically modified [66] or formulated with NP-based delivery methods to improve bioavailability $[67,68]$. Moreover, GNP-based delivery was used for flavonoids with improved bioavailability $[15,69]$. These studies encouraged us to develop a GNP-based delivery system for a 
flavonoid, DHF, which is very commonly used for neurological diseases but has rarely been tested for antimicrobial studies. The functionalization of DHF with GNP increases its water solubility and stability. Only 8-10\% of DHF was found to be associated with GNP. However, the antileishmanial efficacy of DHF-GNP is much higher than the DHF. This is possible because GNP, as such, like c-GNP, is very effective against promastigotes and amastigotes forms of LD. The biggest advantage of synthesized DHF-GNP is its high biocompatibility, which is almost comparable with free DHF. Drug-resistance against standard chemotherapeutic agents is very common in leishmaniasis. Therefore, the use of DHF-GNP, which shows equal efficiency against both sensitive and drug-resistant parasites with high biocompatibility, may provide a new opportunity in the treatment of VL and CL where NP-based delivery has shown promises $[70,71]$. In this study, we found inhibition of arginase as the major cause of parasite death in vitro after DHF and DHF-GNP treatment. This was confirmed by gene expression and enzyme-based assays for arginase followed by supplementation assay in the presence of ornithine, where an increase in cell survival was observed in a dose-dependent manner. There are reports of natural and synthetic molecules with antileishmanial effects targeting the parasite arginase. This is possible since the structure of host and parasite arginase differs considerably [72]. To date, based on crystal structure-based studies, two arginine analogs with the highest inhibition for parasite arginase were reported [73]. A synthetic analog of arginine, $\mathrm{N} \omega$-hydroxy-L-arginine (NOHA), showed a 4-fold reduction in lesion size and as much as 4 million fold reduction in parasite burden in mice model [74]. This shows the future of arginase inhibitors as potential drug targets against leishmaniasis. Our result on DHF-GNP provides enough evidence to encourage its future investigation as a potential antileishmanial agent targeting the parasite arginase.

\section{Abbreviations}

ARG, Arginase; ODC, Ornithine decarboxylase; SpdS, Spermidine synthase; MDR1, Multidrug resistance protein 1; AdoMetDC, TryS, TryR, APx, SOD, AAP3; IFN-y, interferon- - ; iNOS, inducible nitric oxide synthase; IL-interleukin 10, RNS, reactive nitrogen species

\section{Declarations}

\section{Author's contributions}

PP, PK, SM, TP and DM designed research; PP, PK, SM, TP, SK, UHS performed research; PP, PD, VR and DM analyzed data; PP, PD, DM wrote the paper. All authors read and approved the final manuscript.

\section{Author's Details}

${ }^{1}$ Department of Biotechnology, National Institute of Pharmaceutical Education and Research (NIPER) Hajipur 844102, India

${ }^{2}$ Department of Chemistry, Indian Institute of Technology Patna 801106, India

${ }^{3}$ Present address: Cognizant Technology Solution, Hyderabad 800051, India 
${ }^{4}$ Clinical and Translational Research, Chittaranjan National Cancer Institute. Kolkata- 700026, India

${ }^{5}$ National Institute of Pharmaceutical Education and Research (NIPER) - Kolkata 700054, India

\section{Funding}

The funding for this research work was provided by the Ministry of Chemicals and Fertilizers, Government of India.

\section{Acknowledgment}

We acknowledge the financial assistance in research funding to Dr. Debabrata Mandal and PhD fellowship to Pragya Prasanna, Prakash Kumar and Saurabh Kumar from the Ministry of Chemicals and Fertilizers, Government of India. Authors thank IIT-Patna and Chittaranjan National Cancer InstituteKolkata for infrastructure and experimental facilities.

\section{Competing Interests}

The authors report no conflicts of interest in this work.

\section{References}

[1] Z. Miao, Z. Gao, R. Chen, X. Yu, Z. Su, G. Wei, Surface-bioengineered gold nanoparticles for biomedical applications, Curr. Med. Chem. 25 (2018). https://doi.org/10.2174/0929867325666180117111404.

[2] H. Jahangirian, K. Kalantari, Z. Izadiyan, R. Rafiee-Moghaddam, K. Shameli, T.J. Webster, $<p>A$ review of small molecules and drug delivery applications using gold and iron nanoparticles $</ p>$, Int. J. Nanomedicine. Volume 14 (2019) 1633-1657. https://doi.org/10.2147/IJN.S184723.

[3] P. Kumar, P. Shivam, S. Mandal, P. Prasanna, S. Kumar, S.R. Prasad, A. Kumar, P. Das, V. Ali, S.K. Singh, D. Mandal, $<p>$ Synthesis, characterization, and mechanistic studies of a gold nanoparticle-amphotericin B covalent conjugate with enhanced antileishmanial efficacy and reduced cytotoxicity $</ p>$, Int. J. Nanomedicine. Volume 14 (2019) 6073-6101. https://doi.org/10.2147/IJN.S196421.

[4] S. Das, P. Roy, S. Mondal, T. Bera, A. Mukherjee, One pot synthesis of gold nanoparticles and application in chemotherapy of wild and resistant type visceral leishmaniasis, Colloids Surfaces B Biointerfaces. 107 (2013) 27-34. https://doi.org/10.1016/j.colsurfb.2013.01.061.

[5] S. Wu, X. Yang, F. Luo, T. Wu, P. Xu, M. Zou, J. Yan, Biosynthesis of flower-shaped Au nanoclusters with EGCG and their application for drug delivery, J. Nanobiotechnology. 16 (2018) 1-14. https://doi.org/10.1186/s12951-018-0417-3.

[6] A. Graczyk, R. Pawlowska, D. Jedrzejczyk, A. Chworos, Gold nanoparticles in conjunction with nucleic acids as a modern molecular system for cellular delivery, Molecules. 25 (2020). 
https://doi.org/10.3390/molecules25010204.

[7] S. Yadav, A.K. Sharma, P. Kumar, Nanoscale Self-Assembly for Therapeutic Delivery, Front. Bioeng. Biotechnol. 8 (2020). https://doi.org/10.3389/fbioe.2020.00127.

[8] G.R. Rudramurthy, M.K. Swamy, U.R. Sinniah, A. Ghasemzadeh, Nanoparticles: Alternatives against drug-resistant pathogenic microbes, Molecules. 21 (2016). https://doi.org/10.3390/molecules21070836.

[9] M.N. Uddin, F. Desai, E. Asmatulu, Engineered nanomaterials in the environment: bioaccumulation, biomagnification and biotransformation, Environ. Chem. Lett. (2020) 1-11. https://doi.org/10.1007/s10311-019-00947-0.

[10] A.K. Mittal, Y. Chisti, U.C. Banerjee, Synthesis of metallic nanoparticles using plant extracts, Biotechnol. Adv. 31 (2013) 346-356. https://doi.org/10.1016/j.biotechadv.2013.01.003.

[11] M. Das, S. Chatterjee, Green synthesis of metal/metal oxide nanoparticles toward biomedical applications: Boon or bane, in: Green Synth. Charact. Appl. Nanoparticles, Elsevier, 2019: pp. 265-301. https://doi.org/10.1016/b978-0-08-102579-6.00011-3.

[12] H. Agarwal, S. Venkat Kumar, S. Rajeshkumar, A review on green synthesis of zinc oxide nanoparticles - An eco-friendly approach, Resour. Technol. 3 (2017) 406-413. https://doi.org/10.1016/j.reffit.2017.03.002.

[13] J. Singh, T. Dutta, K.H. Kim, M. Rawat, P. Samddar, P. Kumar, "Green" synthesis of metals and their oxide nanoparticles: Applications for environmental remediation, J. Nanobiotechnology. 16 (2018) 1-24. https://doi.org/10.1186/s12951-018-0408-4.

[14] Q. Han, X. Wang, S. Cai, X. Liu, Y. Zhang, L. Yang, C. Wang, R. Yang, Quercetin nanoparticles with enhanced bioavailability as multifunctional agents toward amyloid induced neurotoxicity, J. Mater. Chem. B. 6 (2018) 1387-1393. https://doi.org/10.1039/c7tb03053c.

[15] S. Mukherjee, S. Ghosh, D.K. Das, P. Chakraborty, S. Choudhury, P. Gupta, A. Adhikary, S. Dey, S. Chattopadhyay, Gold-conjugated green tea nanoparticles for enhanced anti-tumor activities and hepatoprotection - synthesis, characterization and in vitro evaluation, J. Nutr. Biochem. 26 (2015) 12831297. https://doi.org/10.1016/j.jnutbio.2015.06.003.

[16] P. Thamaket, P. Raviyan, Preparation and physical properties of carotenoids encapsulated in chitosan cross-linked tripolyphosphate nanoparticles, 3 (2015) 69-84.

[17] S. Jain, M.S. Mehata, Medicinal Plant Leaf Extract and Pure Flavonoid Mediated Green Synthesis of Silver Nanoparticles and their Enhanced Antibacterial Property, Sci. Rep. 7 (2017). https://doi.org/10.1038/s41598-017-15724-8. 
[18] G. Marslin, K. Siram, Q. Maqbool, R.K. Selvakesavan, D. Kruszka, P. Kachlicki, G. Franklin, Secondary metabolites in the green synthesis of metallic nanoparticles, Materials (Basel). 11 (2018) 1-25. https://doi.org/10.3390/ma11060940.

[19] G.L. Hostetler, R.A. Ralston, S.J. Schwartz, Flavones: Food Sources, Bioavailability, Metabolism, and Bioactivity, Adv. Nutr. An Int. Rev. J. 8 (2017) 423-435. https://doi.org/10.3945/an.116.012948.

[20] A.N. Panche, A.D. Diwan, S.R. Chandra, Flavonoids: An overview, J. Nutr. Sci. 5 (2016). https://doi.org/10.1017/jns.2016.41.

[21] V. Gopinath, S. Priyadarshini, M. Fai, J. Arunkumar, E. Marsili, D. Mubarakali, P. Velusamy, J. Vadivelu, Biogenic synthesis , characterization of antibacterial silver nanoparticles and its cell cytotoxicity, Arab. J. Chem. 10 (2017) 1107-1117. https://doi.org/10.1016/j.arabjc.2015.11.011.

[22] X. Li, W. Luo, T.W. Ng, P.C. Leung, C. Zhang, K.C.F. Leung, L. Jin, Nanoparticle-encapsulated baicalein markedly modulates pro-inflammatory response in gingival epithelial cells, Nanoscale. 9 (2017) 1289712907. https://doi.org/10.1039/c7nr02546g.

[23] M. Hussain, N.I. Raja, M. Iqbal, S. Aslam, Applications of Plant Flavonoids in the Green Synthesis of Colloidal Silver Nanoparticles and Impacts on Human Health Applications of Plant Flavonoids in the Green Synthesis of Colloidal Silver Nanoparticles and Impacts on Human Health, Iran. J. Sci. Technol. Trans. A Sci. (2017). https://doi.org/10.1007/s40995-017-0431-6.

[24] L.G. Sarbu, L.G. Bahrin, C. Babii, M. Stefan, M.L. Birsa, Synthetic flavonoids with antimicrobial activity: a review, J. Appl. Microbiol. 127 (2019) 1282-1290. https://doi.org/10.1111/jam.14271.

[25] F. Chappuis, S. Sundar, A. Hailu, H. Ghalib, S. Rijal, R.W. Peeling, J. Alvar, M. Boelaert, Visceral leishmaniasis: What are the needs for diagnosis, treatment and control?, Nat. Rev. Microbiol. 5 (2007) 873-882. https://doi.org/10.1038/nrmicro1748.

[26] M. Tullius Scotti, L. Scotti, H. Ishiki, F. Fávaro Ribeiro, R. Marques Duarte da Cruz, M. Pedrosa de Oliveira, F. Jaime Bezerra Mendonça, Natural Products as a Source for Antileishmanial and Antitrypanosomal Agents, Comb. Chem. High Throughput Screen. 19 (2016) 537-553. https://doi.org/10.2174/1386207319666160506123921.

[27] P.K. Boniface, E.I. Ferreira, Flavonoids as efficient scaffolds: Recent trends for malaria, leishmaniasis, Chagas disease, and dengue, Phyther. Res. 33 (2019) 2473-2517. https://doi.org/10.1002/ptr.6383.

[28] D. Tasdemir, M. Kaiser, R. Brun, V. Yardley, T.J. Schmidt, F. Tosun, P. Ru, Antitrypanosomal and Antileishmanial Activities of Flavonoids and Their Analogues: In Vitro, In Vivo, Structure-Activity Relationship , and Quantitative Structure-Activity Relationship Studies, 50 (2006) 1352-1364. https://doi.org/10.1128/AAC.50.4.1352. 
[29] P.M. Cheuka, G. Mayoka, P. Mutai, K. Chibale, The role of natural products in drug discovery and development against neglected tropical diseases, Molecules. 22 (2017). https://doi.org/10.3390/molecules22010058.

[30] C. Liu, C.B. Chan, K. Ye, 7,8-dihydroxyflavone, a small molecular TrkB agonist, is useful for treating various BDNF-implicated human disorders, Transl. Neurodegener. 5 (2016).

https://doi.org/10.1186/s40035-015-0048-7.

[31] X. Han, S. Zhu, B. Wang, L. Chen, R. Li, W. Yao, Z. Qu, Antioxidant action of 7,8-dihydroxyflavone protects PC12 cells against 6-hydroxydopamine-induced cytotoxicity, Neurochem. Int. 64 (2014) 18-23. https://doi.org/10.1016/j.neuint.2013.10.018.

[32] Z. Jin, Y.Z. Yang, J.X. Chen, Y.Z. Tang, Inhibition of pro-inflammatory mediators in RAW264.7 cells by 7-hydroxyflavone and 7,8-dihydroxyflavone, J. Pharm. Pharmacol. 69 (2017) 865-874. https://doi.org/10.1111/jphp.12714.

[33] P.P. Carneiro, J. Conceição, M. Macedo, V. Magalhães, E.M. Carvalho, O. Bacellar, The role of nitric oxide and reactive oxygen species in the killing of Leishmania braziliensis by monocytes from patients with cutaneous leishmaniasis, PLoS One. 11 (2016). https://doi.org/10.1371/journal.pone.0148084.

[34] B. Purkait, A. Kumar, N. Nandi, A.H. Sardar, S. Das, S. Kumar, K. Pandey, V. Ravidas, M. Kumar, T. De, D. Singh, P. Das, Mechanism of amphotericin B resistance in clinical isolates of Leishmania donovani, Antimicrob. Agents Chemother. 56 (2012) 1031-1041. https://doi.org/10.1128/AAC.00030-11.

[35] J.J.M. De Llano, E.J. Andreu, A. Pastor, M. De La Guardia, E. Knecht, Electrothermal atomic absorption spectrometric diagnosis of familial hypercholesterolemia, Anal. Chem. 72 (2000) 2406-2413. https://doi.org/10.1021/ac991287p.

[36] Y. Xiao, W. Xu, Y. Komohara, Y. Fujiwara, H. Hirose, S. Futaki, T. Niidome, Effect of Surface Modifications on Cellular Uptake of Gold Nanorods in Human Primary Cells and Established Cell Lines, ACS Omega. 5 (2020) 32744-32752. https://doi.org/10.1021/acsomega.0c05162.

[37] J. Trono, K. Mizuno, N. Yusa, T. Matsukawa, M. Uesaka, Cellular uptake of gold nanoparticles into normal and cancer cells, IFMBE Proc. 25 (2009) 202-205. https://doi.org/10.1007/978-3-642-038877_56.

[38] J.D. Trono, K. Mizuno, N. Yusa, T. Matsukawa, K. Yokoyama, M. Uesaka, Size, concentration and incubation time dependence of gold nanoparticle uptake into pancreas cancer cells and itsfuture application to X-ray drug delivery system, J. Radiat. Res. 52 (2011) 103-109. https://doi.org/10.1269/jrr.10068.

[39] E.A. Britta, D.B. Scariot, H. Falzirolli, T. Ueda-Nakamura, C.C. Silva, B.P.D. Filho, R. Borsali, C.V. Nakamura, Cell death and ultrastructural alterations in Leishmania amazonensis caused by new 
compound 4-Nitrobenzaldehyde thiosemicarbazone derived from S-limonene, BMC Microbiol. 14 (2014) 236. https://doi.org/10.1186/s12866-014-0236-0.

[40] M. Sechi, V. Sanna, N. Pala, P. Manconi, A. Mariani, S. Dedola, M. Rassu, C. Crosio, C. Iaccarino, G. Dessi, Single-step green synthesis and characterization of gold-conjugated polyphenol nanoparticles with\&amp;nbsp;antioxidant\&amp;nbsp;and biological activities, Int. J. Nanomedicine. 9 (2014) 4935. https://doi.org/10.2147/IJN.S70648.

[41] A. Badirzadeh, T. Taheri, Y. Taslimi, Z. Abdossamadi, M. Heidari-Kharaji, E. Gholami, B. Sedaghat, M. Niyyati, S. Rafati, Arginase activity in pathogenic and non-pathogenic species of Leishmania parasites, PLoS Negl. Trop. Dis. 11 (2017) 1-22. https://doi.org/10.1371/journal.pntd.0005774.

[42] S. Mondal, P. Roy, S. Das, A. Halder, A. Mukherjee, T. Bera, In Vitro susceptibilities of wild and drug resistant Leishmania donovani amastigote stages to andrographolide nanoparticle: Role of vitamin e derivative TPGS for nanoparticle efficacy, PLoS One. 8 (2013).

https://doi.org/10.1371/journal.pone.0081492.

[43] I.M. Corraliza, M.L. Campo, G. Soler, M. Modolell, Determination of arginase activity in macrophages: a micromethod, J. Immunol. Methods. 174 (1994) 231-235. https://doi.org/10.1016/00221759(94)90027-2.

[44] J.M. Boitz, C.A. Gilroy, T.D. Olenyik, D. Paradis, J. Perdeh, K. Dearman, M.J. Davis, P.A. Yates, Y. Li, M.K. Riscoe, B. Ullman, S.C. Roberts, Arginase is essential for survival of Leishmania donovani promastigotes but not intracellular amastigotes, Infect. Immun. 85 (2017) 1-14.

https://doi.org/10.1128/IAI.00554-16.

[45] D. Resistance, In Vitro Evaluation of Antileishmanial Activity of Computationally Screened Compounds against Ascorbate, 61 (2017) 1-25.

[46] F. Chappuis, S. Sundar, A. Hailu, H. Ghalib, S. Rijal, R.W. Peeling, J. Alvar, M. Boelaert, Visceral leishmaniasis: What are the needs for diagnosis, treatment and control?, Nat. Rev. Microbiol. 5 (2007) 873-882. https://doi.org/10.1038/nrmicro1748.

[47] O.P. Singh, E. Hasker, M. Boelaert, S. Sundar, Elimination of visceral leishmaniasis on the Indian subcontinent, Lancet Infect. Dis. 16 (2016) e304-e309. https://doi.org/10.1016/S1473-3099(16)30140-2.

[48] Y. Mueller, A. Nguimfack, P. Cavailler, S. Couffignal, J.B. Rwakimari, L. Loutan, F. Chappuis, Safety and effectiveness of amphotericin B deoxycholate for the treatment of visceral leishmaniasis in Uganda, Ann. Trop. Med. Parasitol. 102 (2008) 11-19. https://doi.org/10.1179/136485908X252142.

[49] S. Sundar, P.K. Sinha, M. Rai, D.K. Verma, K. Nawin, S. Alam, J. Chakravarty, M. Vaillant, N. Verma, K. Pandey, P. Kumari, C.S. Lal, R. Arora, B. Sharma, S. Ellis, N. Strub-Wourgaft, M. Balasegaram, P. Olliaro, P. Das, F. Modabber, Comparison of short-course multidrug treatment with standard therapy for visceral 
leishmaniasis in India: An open-label, non-inferiority, randomised controlled trial, Lancet. 377 (2011) 477486. https://doi.org/10.1016/S0140-6736(10)62050-8.

[50] S. Mistro, B. Gomes, L. Rosa, L. Miranda, M. Camargo, R. Badaró, Cost-effectiveness of liposomal amphotericin B in hospitalised patients with mucocutaneous leishmaniasis, Trop. Med. Int. Heal. 22 (2017) 1569-1578. https://doi.org/10.1111/tmi.12996.

[51] H.H.L. Borba, L.M. Steimbach, B.S. Riveros, F.S. Tonin, V.L. Ferreira, B.A. de Q. Bagatim, G. Balan, R. Pontarolo, A. Wiens, Cost-effectiveness of amphotericin B formulations in the treatment of systemic fungal infections, Mycoses. 61 (2018) 754-763. https://doi.org/10.1111/myc.12801.

[52] M. Salem, K. Werbovetz, Natural Products from Plants as Drug Candidates and Lead Compounds Against Leishmaniasis and Trypanosomiasis, Curr. Med. Chem. 13 (2006) 2571-2598. https://doi.org/10.2174/092986706778201611.

[53] T.J. Schmidt, S.A. Khalid, A.J. Romanha, T.MA. Alves, M.W. Biavatti, R. Brun, F.B. Da Costa, S.L. de Castro, V.F. Ferreira, M.V.G. de Lacerda, J.H.G. Lago, L.L. Leon, N.P. Lopes, R.C. das Neves Amorim, M. Niehues, I.V. Ogungbe, The Potential of Secondary Metabolites from Plants as Drugs or Leads Against Protozoan Neglected Diseases - Part I, Curr. Med. Chem. 19 (2012) 2128-2175. https://doi.org/10.2174/092986712800229023.

[54] N. Kar, S. Chakraborty, A.K. De, S. Ghosh, T. Bera, Development and evaluation of a cedrol-loaded nanostructured lipid carrier system for in vitro and in vivo susceptibilities of wild and drug resistant Leishmania donovani amastigotes, Eur. J. Pharm. Sci. 104 (2017) 196-211. https://doi.org/10.1016/j.ejps.2017.03.046.

[55] S. Das, A. Halder, S. Mandal, M.A.J. Mazumder, T. Bera, A. Mukherjee, P. Roy, Andrographolide engineered gold nanoparticle to overcome drug resistant visceral leishmaniasis, Artif. Cells, Nanomedicine Biotechnol. 46 (2018) 751-762. https://doi.org/10.1080/21691401.2018.1435549.

[56] A.W. English, K. Liu, J.M. Nicolini, A.M. Mulligan, K. Ye, Small-molecule trkB agonists promote axon regeneration in cut peripheral nerves, Proc. Natl. Acad. Sci. U. S. A. 110 (2013) 16217-16222. https://doi.org/10.1073/pnas.1303646110.

[57] I.L.K. Wong, K.F. Chan, B.A. Burkett, Y. Zhao, Y. Chai, H. Sun, T.H. Chan, L.M.C. Chow, Flavonoid dimers as bivalent modulators for pentamidine and sodium stiboglucanate resistance in Leishmania, Antimicrob. Agents Chemother. 51 (2007) 930-940. https://doi.org/10.1128/AAC.00998-06.

[58] A. Mukherjee, P.K. Padmanabhan, S. Singh, G. Roy, I. Girard, M. Chatterjee, M. Ouellette, R. Madhubala, Role of ABC transporter MRPA, y-glutamylcysteine synthetase and ornithine decarboxylase in natural antimony-resistant isolates of Leishmania donovani, J. Antimicrob. Chemother. 59 (2007) 204-211. https://doi.org/10.1093/jac/dkl494. 
[59] L.C. Manjolin, M.B.G. Dos Reis, C. Do Carmo Maquiaveli, O.A. Santos-Filho, E.R. Da Silva, Dietary flavonoids fisetin, luteolin and their derived compounds inhibit arginase, a central enzyme in Leishmania (Leishmania) amazonensis infection, Food Chem. 141 (2013) 2253-2262. https://doi.org/10.1016/j.foodchem.2013.05.025.

[60] Arnida, M.M. Janát-Amsbury, A. Ray, C.M. Peterson, H. Ghandehari, Geometry and surface characteristics of gold nanoparticles influence their biodistribution and uptake by macrophages, Eur. J. Pharm. Biopharm. 77 (2011) 417-423. https://doi.org/10.1016/j.ejpb.2010.11.010.

[61] K. Jomová, L. Hudecova, P. Lauro, M. Simunkova, S.H. Alwasel, I.M. Alhazza, M. Valko, A switch between antioxidant and prooxidant properties of the phenolic compounds myricetin, morin, 3',4'dihydroxyflavone, taxifolin and 4-hydroxy-coumarin in the presence of copper(II) ions: A spectroscopic, absorption titration and DNA damage study, Molecules. 24 (2019). https://doi.org/10.3390/molecules24234335.

[62] J.I. Aoki, S.M. Muxel, R.A. Zampieri, S.M. Acuña, J.C.R. Fernandes, R.H. Vanderlinde, M.C.O. de P. Sales, L.M. Floeter-Winter, L-arginine availability and arginase activity: Characterization of amino acid permease 3 in Leishmania amazonensis, PLoS Negl. Trop. Dis. 11 (2017).

https://doi.org/10.1371/journal.pntd.0006025.

[63] V. Iniesta, L.C. Gómez-Nieto, I. Corraliza, The inhibition of arginase by N $\omega$-hydroxy-L-arginine controls the growth of Leishmania inside macrophages, J. Exp. Med. 193 (2001) 777-783. https://doi.org/10.1084/jem.193.6.777.

[64] S.C. Roberts, M.J. Tancer, M.R. Polinsky, K. Michael Gibson, O. Heby, B. Ullman, Arginase plays a pivotal role in polyamine precursor metabolism in Leishmania: Characterization of gene deletion mutants, J. Biol. Chem. 279 (2004) 23668-23678. https://doi.org/10.1074/jbc.M402042200.

[65] S. Gordon, Alternative activation of macrophages, Nat. Rev. Immunol. 3 (2003) 23-35. https://doi.org/10.1038/nri978.

[66] T. Walle, Methylation of dietary flavones greatly improves their hepatic metabolic stability and intestinal absorption, Mol. Pharm. 4 (2007) 826-832. https://doi.org/10.1021/mp700071d.

[67] C.C. Yen, C.W. Chang, M.C. Hsu, Y.T. Wu, Self-Nanoemulsifying drug delivery system for resveratrol: Enhanced oral bioavailability and reduced physical fatigue in rats, Int. J. Mol. Sci. 18 (2017). https://doi.org/10.3390/ijms18091853.

[68] Z. Zhang, Y. Huang, F. Gao, Z. Gao, H. Bu, W. Gu, Y. Li, A self-assembled nanodelivery system enhances the oral bioavailability of daidzein: In vivo characteristics and in vivo performance, Nanomedicine. 6 (2011) 1365-1379. https://doi.org/10.2217/nnm.11.39. 
[69] A. Anwar, S. Khalid, S. Perveen, S. Ahmed, R. Siddiqui, N.A. Khan, M.R. Shah, Synthesis of 4(dimethylamino)pyridine propylthioacetate coated gold nanoparticles and their antibacterial and photophysical activity, J. Nanobiotechnology. 16 (2018). https://doi.org/10.1186/s12951-017-0332-z.

[70] T.G. Ribeiro, M.A. Chávez-Fumagall, D.G. Valadares, J.R. França, L.B. Rodrigues, M.C. Duarte, P.S. Lage, P.H.R. Andrade, D.P. Lage, L. V. Arruda, C. Refidaff, L.E. Costa, V.T. Martins, C.A.P. Tavares, R.O. Castilho, E.A.F. Coelho, A.A.G. Faraco, Novel targeting using nanoparticles: An approach to the development of an effective anti-leishmanial drug-delivery system, Int. J. Nanomedicine. 9 (2014) 877890. https://doi.org/10.2147/IJN.S55678.

[71] N. Bruni, B. Stella, L. Giraudo, C. Della Pepa, D. Gastaldi, F. Dosio, Nanostructured delivery systems with improved leishmanicidal activity: A critical review, Int. J. Nanomedicine. 12 (2017) 5289-5311. https://doi.org/10.2147/IJN.S140363.

[72] E. Riley, S.C. Roberts, B. Ullman, Inhibition profile of Leishmania mexicana arginase reveals differences with human arginase I, Int. J. Parasitol. 41 (2011) 545-552. https://doi.org/10.1016/j.jpara.2010.12.006.

[73] E.L. D’Antonio, B. Ullman, S.C. Roberts, U.G. Dixit, M.E. Wilson, Y. Hai, D.W. Christianson, Crystal structure of arginase from Leishmania mexicana and implications for the inhibition of polyamine biosynthesis in parasitic infections, Arch. Biochem. Biophys. 535 (2013) 163-176. https://doi.org/10.1016/j.abb.2013.03.015.

[74] P. Kropf, J.M. Fuentes, E. Fähnrich, L. Arpa, S. Herath, V. Weber, G. Soler, A. Celada, M. Modolell, I. Müller, Arginase and polyamine synthesis are key factors in the regulation of experimental leishmaniasis in vivo, FASEB J. 19 (2005) 1000-1002. https://doi.org/10.1096/fj.04-3416fje.

\section{Supplemental Figure Legends}

Supplementary Figure S1. Characterization of DHF-GNPs by Zeta potential studies (A) and by DLS studies (B).

Supplementary Figure S2. Dose-response curve of DHF, DHF-GNP, and c-GNP after $72 \mathrm{~h}$ treatment against (A) promastigotes in vitro and (B) intracellular amastigotes ex vivo

Supplementary Figure S3. Estimation of reactive nitrogen species in macrophages by Griess reagent after DHF, DHF-GNP, and c-GNP treatment.

Supplementary Figure S4. (A) Antioxidant activities of DHF (5-80 $\mu \mathrm{M})$, DHF-GNPs (5-80 $\mu \mathrm{M})$ measured by percentage inhibition of DPPH scavenging activity. (B) Determination of reactive oxygen species in LD promastigotes treated with DHF $(40-280 \mu \mathrm{M})$, DHF-GNP $(40-280 \mu \mathrm{M})$ and c-GNP $(5 \mu \mathrm{M})$ for 12 hours. 
Supplementary Figure S5. Enzyme assay with LD promastigotes lysates after treatment with DHF (120$240 \mu \mathrm{M})$, DHF-GNP $(40-80 \mu \mathrm{M})$ and c-GNP $(20 \mu \mathrm{M})$. (A) Superoxide dismutase assay and (B) Ascorbate peroxidase assay.

Supplementary Figure S6. Semi-quantitative PCR for different genes on promastigotes after treatment with DHF and DHF-GNP at IC $\mathrm{I}_{50}$ dose for $24 \mathrm{~h}(\mathrm{~A})$ and after treatment with $2 \times \mathrm{IC}_{50}$ doses for $8 \mathrm{~h}(\mathrm{~B})$.

Supplementary Figure S7. Semi-quantitative PCR for genes of amastigote-infected macrophages after treatment with DHF and DHF-GNP with $2 \times \mathrm{IC}_{50}$ doses for $8 \mathrm{~h}$

Supplementary Figure S8. Characterization studies of c-GNPs by DLS (B) and Transmission electron microscopy (B).

\section{Figures}

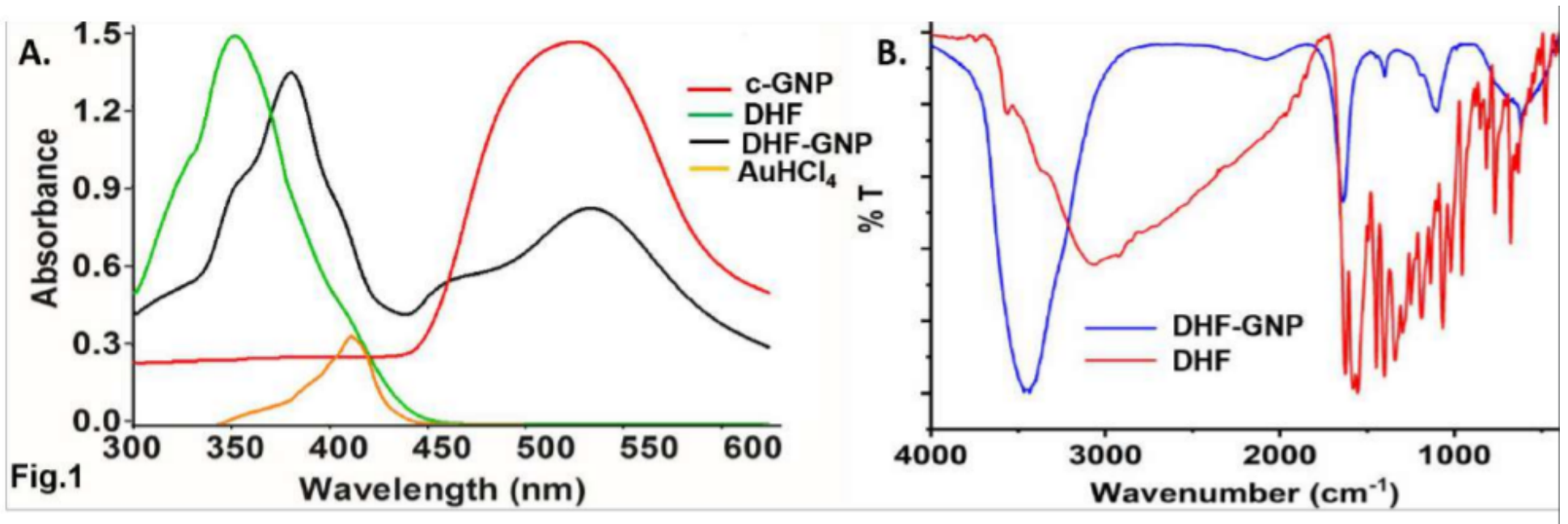

Figure 1

(A) The UV-Vis absorbance spectra of DHF, DHF-GNP, and c-GNP. (B) Fourier-transform infrared spectra of DHF-GNPs compared with pure DHF. 


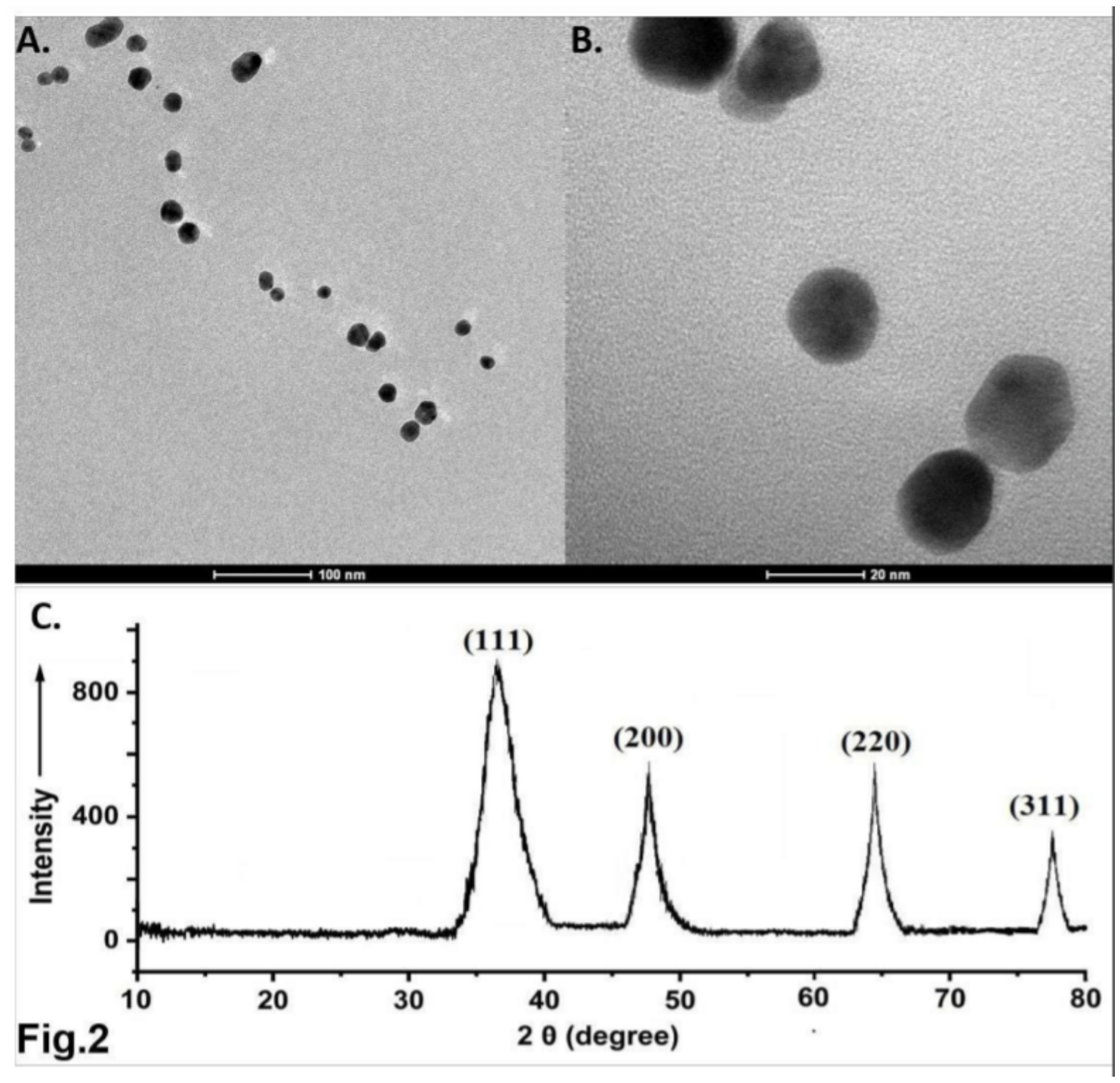

Figure 2

Transmission electron microscopy (TEM) micrographs of DHF-GNP at (A) $100 \mathrm{~nm}$ and (B) 20nm scale. (C) X-ray diffraction pattern of DHF-GNP. 

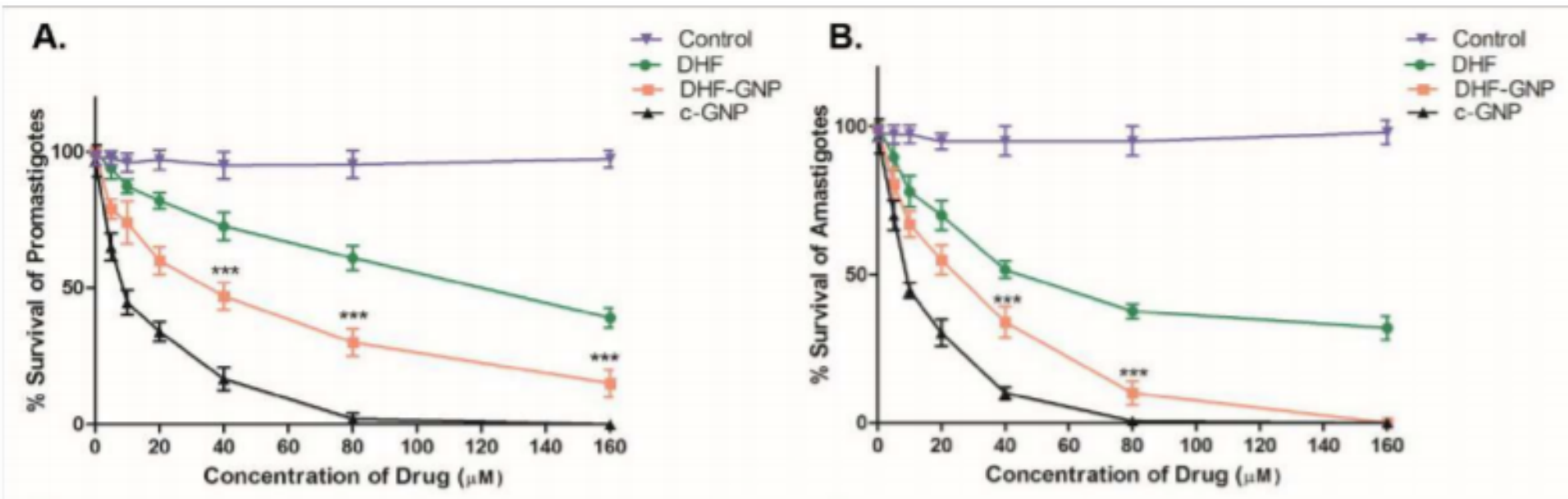

C.
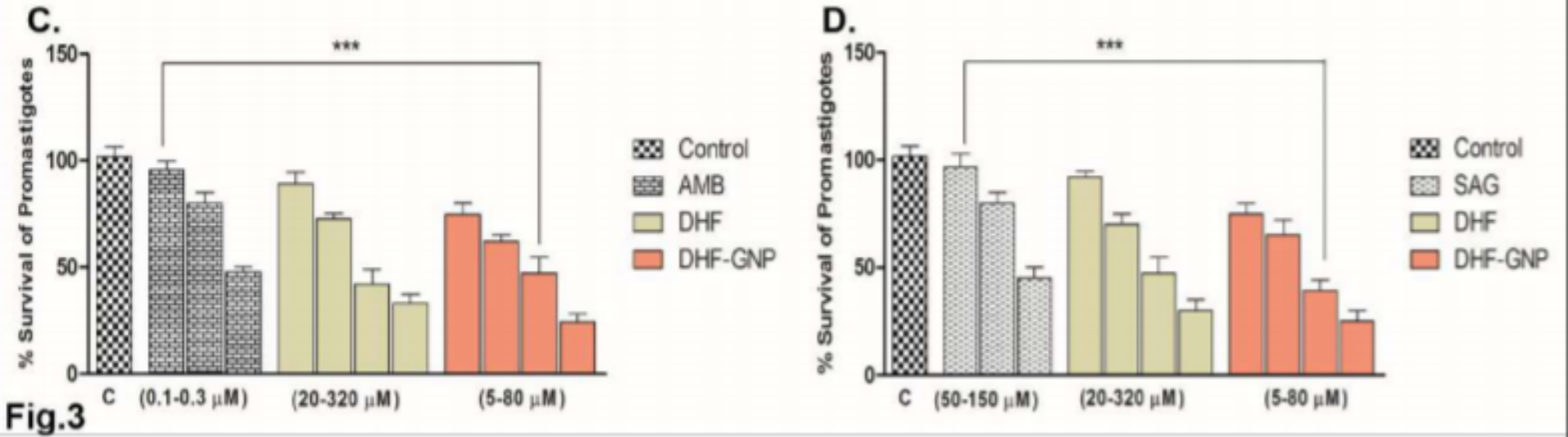

\section{Figure 3}

Dose-response curve of DHF, DHF-GNP, and c-GNP after $48 \mathrm{~h}$ treatment against (A) promastigotes in vitro and (B) intracellular amastigotes ex vivo. Dose-response curve against (C) amphotericin B-resistant promastigotes and (D) SAG-resistant promastigotes. 
A.
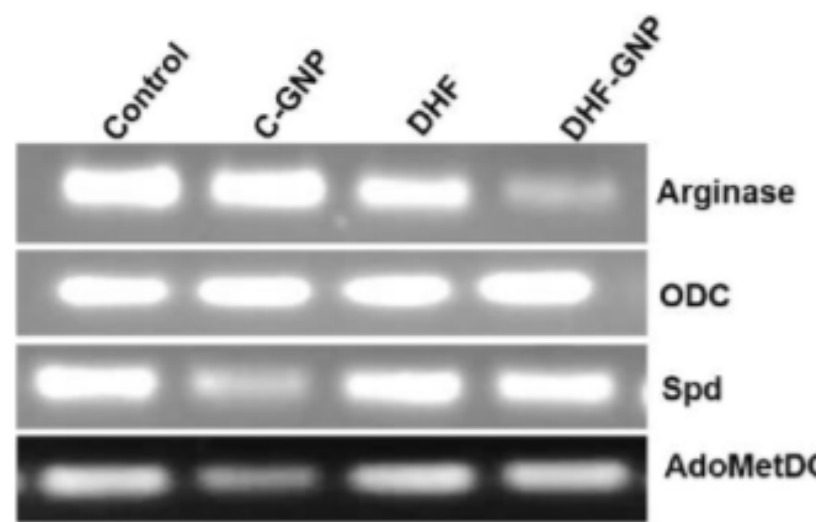

Spd

AdoMetDC

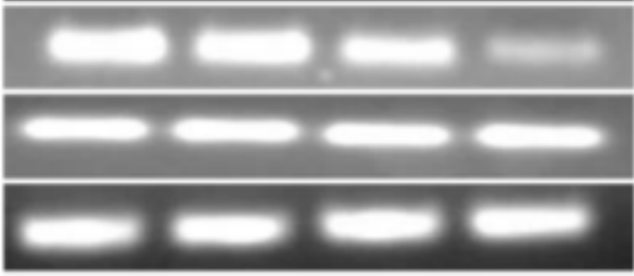

TryS
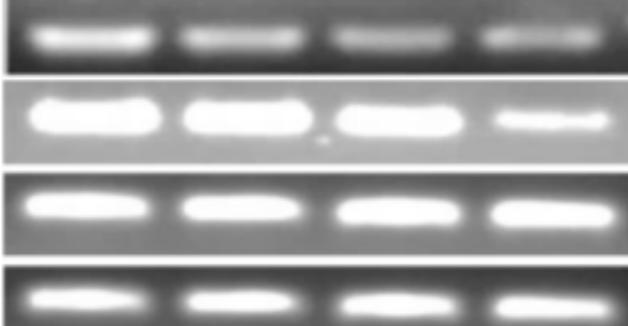

Fig.4

AAP3
a-Tubulin

GAPDH

TryR

SOD

APx

MDR 1

AAP3
a-Tubulin
B.
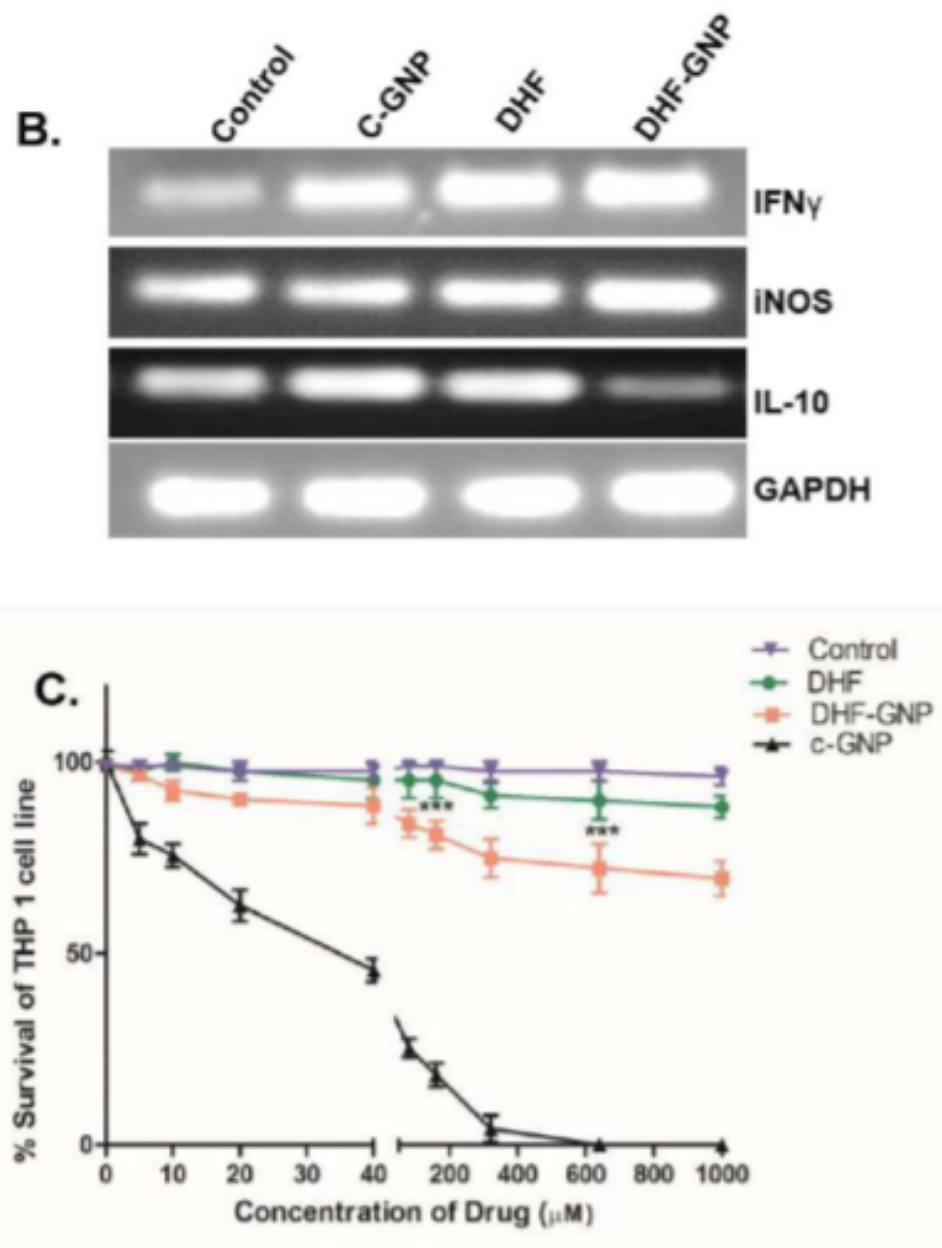

\section{Figure 4}

Semi-quantitative PCR for genes of polyamine biosynthesis pathway of promastigotes $(A)$ and genes of IFN- $y$, iNOS, IL-10 of macrophages (B). (C) Cytotoxicity assay on THP-1 cells after $48 \mathrm{~h}$ treatment with different concentrations of DHF, DHF-GNP, and c-GNP. 

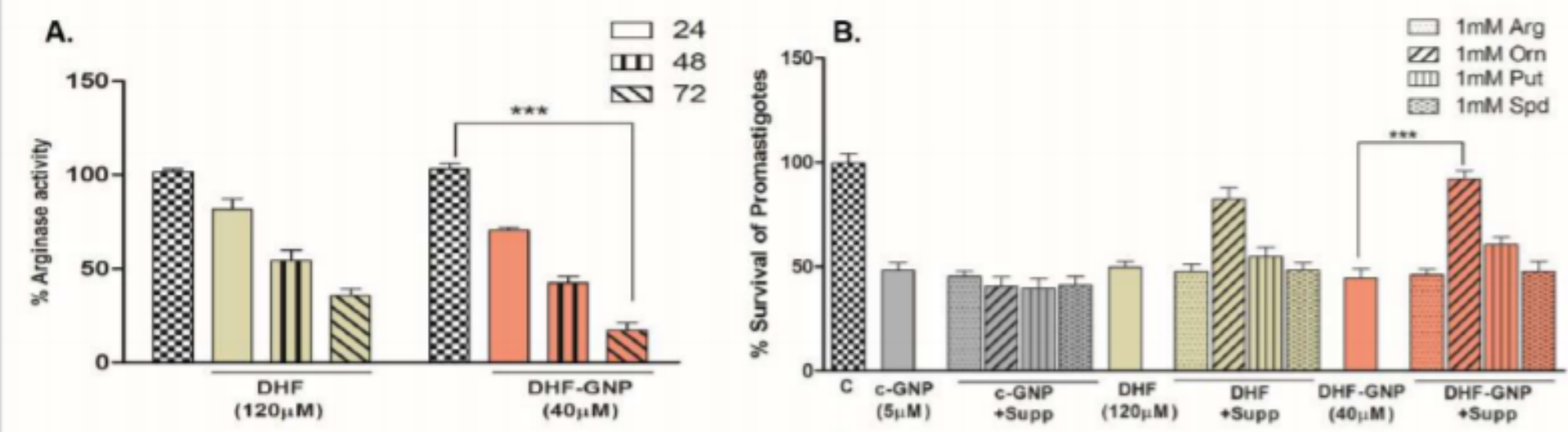

c.

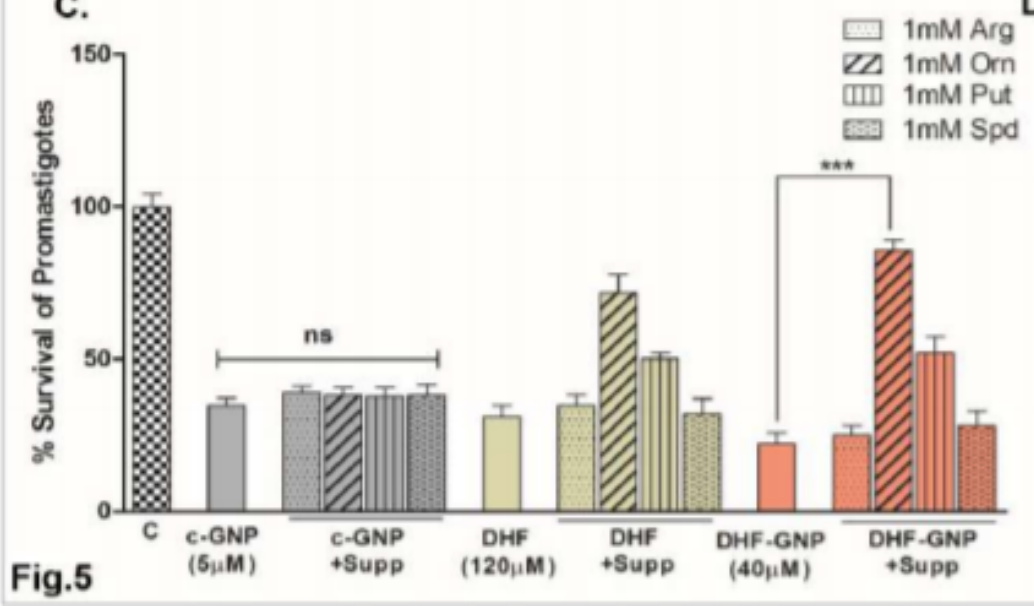

D.

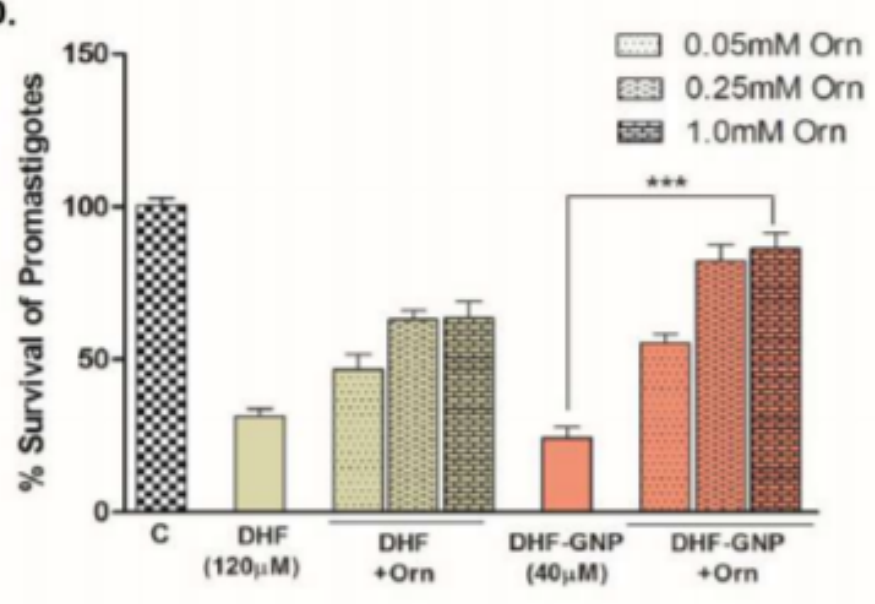

Figure 5

(A) Time course of arginase assay with DHF and DHF-GNP treated promastigote cell lysates.

Supplementation assay with pre-incubation of $1 \mathrm{mM}$ arginine (Arg), ornithine (Orn), putrescine (Put), spermidine (Spd) for DHF, and DHF-GNP and c-GNP treated cells (B) after $48 \mathrm{~h}$ and (C) $72 \mathrm{~h}$. (D) Supplementation assay with different doses of ornithine $(0.05,0.25$, and $1 \mathrm{mM})$ for DHF and DHF-GNP and c-GNP treated cells after $48 \mathrm{~h}$. 


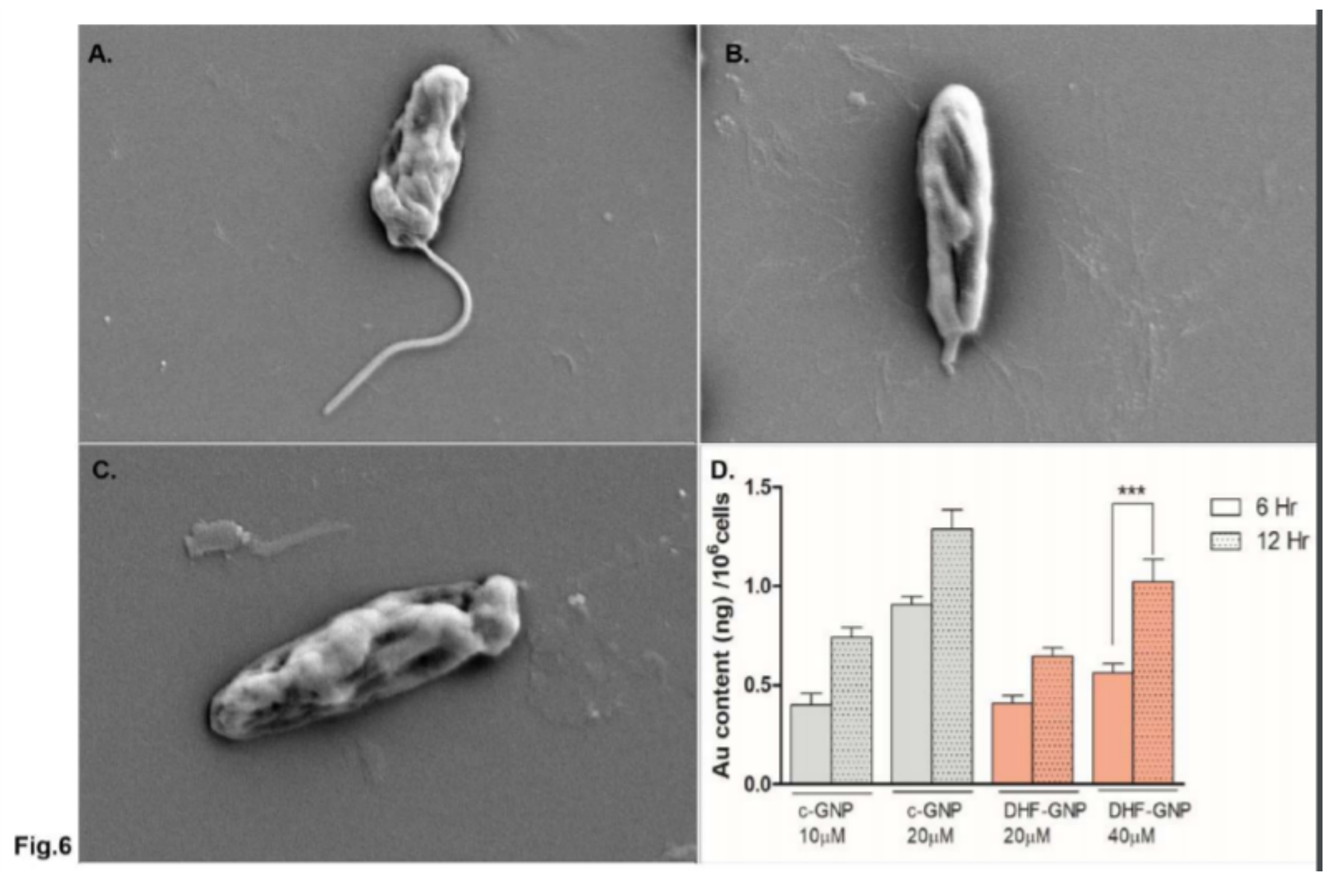

Figure 6

Scanning electron microscopy of Leishmania donovani promastigotes $(A)$ and promastigotes treated with DHF-GNP (B) and c-GNP (C). Uptake of gold nanoparticles by RAW 264.1 cells detected by AAS (D) 


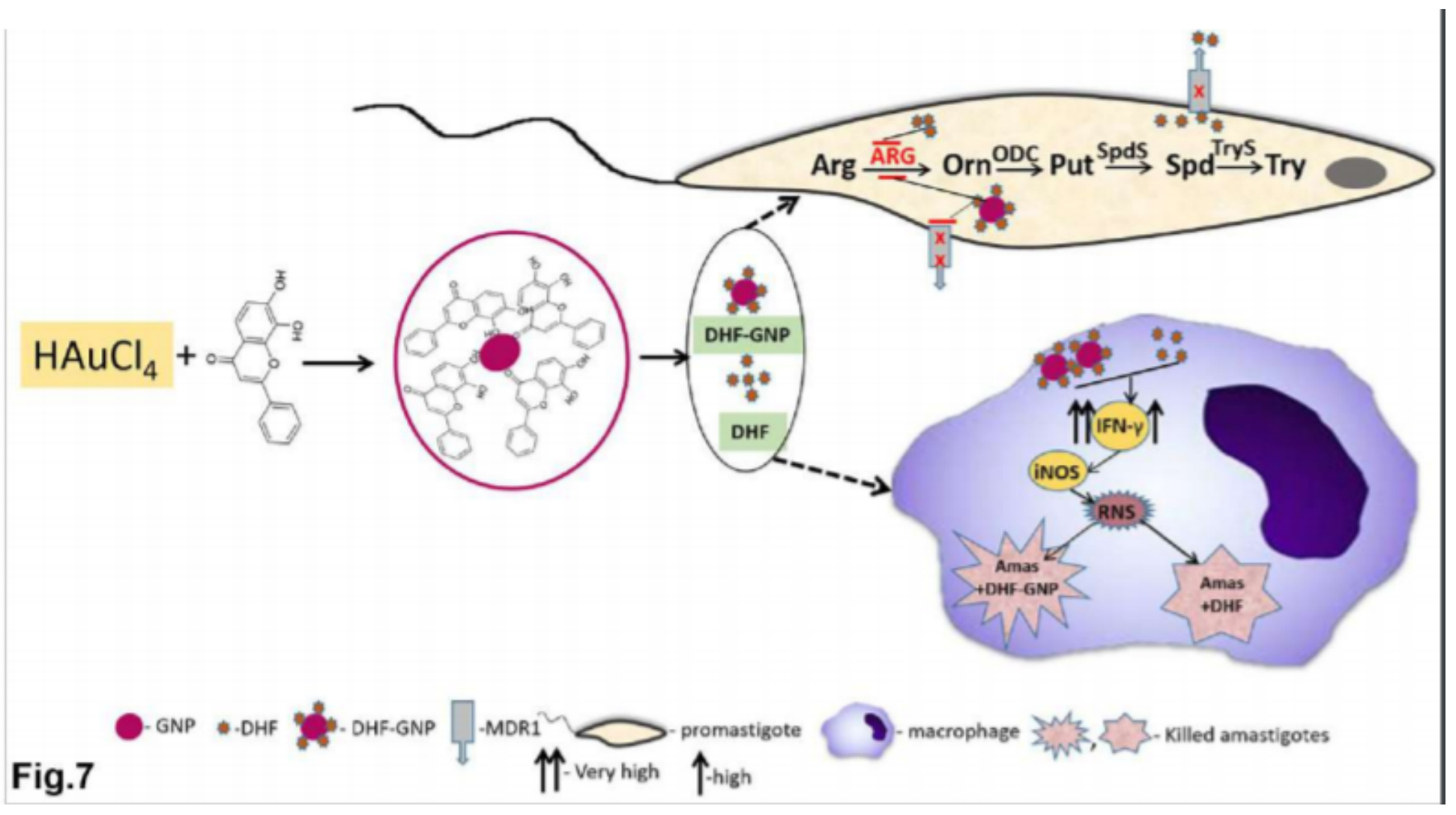

Figure 7

Graphical abstract showing the role DHF and DHF-GNP against promastigotes (targeting arginase and MDR1) and against amastigotes with elevated Th1 cytokine-mediated iNOS activity and RNS-mediated killing.

\section{Supplementary Files}

This is a list of supplementary files associated with this preprint. Click to download.

- GraphicalAbstract.pdf

- MergedSupplementaryFigures.pdf

- SupplementaryTable1.pdf 